\title{
The Beginning of the Christian Era Revisited: New Findings
}

\author{
Liberato De Caro $^{1}$ (D), Fernando La Greca ${ }^{2}$ and Emilio Matricciani ${ }^{3, *(D)}$ \\ 1 Istituto di Cristallografia, Consiglio Nazionale delle Ricerche, IC-CNR, 70126 Bari, Italy; \\ liberato.decaro@ic.cnr.it \\ 2 Dipartimento di Studi Umanistici, Università degli Studi di Salerno, 84084 Fisciano, Italy; flagreca@unisa.it \\ 3 Dipartimento di Elettronica, Informazione e Bioingegneria, Politecnico di Milano, 20133 Milano, Italy \\ * Correspondence: emilio.matricciani@polimi.it
}

Citation: De Caro, L.; La Greca, F.; Matricciani, E. The Beginning of the Christian Era Revisited: New Findings. Histories 2021, 1, 145-168. https://doi.org/10.3390/

histories 1030016

Academic Editor: Jon Mathieu

Received: 10 June 2021

Accepted: 2 August 2021

Published: 11 August 2021

Publisher's Note: MDPI stays neutral with regard to jurisdictional claims in published maps and institutional affiliations.

Copyright: (C) 2021 by the authors. Licensee MDPI, Basel, Switzerland. This article is an open access article distributed under the terms and conditions of the Creative Commons Attribution (CC BY) license (https:// creativecommons.org/licenses/by/ $4.0 /)$.

\begin{abstract}
We have re-examined and discussed all chronological, historical and astronomical elements which can be referred to the year of Herod the Great's death, which occurred-according to Josephusafter a lunar eclipse and before Passover. Since the XIX century, most scholars still assume the eclipse occurred on 13 March 4 BC, so that Dionysius Exiguus was wrong in calculating the beginning of the Christian era-by four years at least-because Herod the Great must have been alive when Jesus was born. We have solved the apparent incompatibility of the events narrated by Josephus, occurring between the eclipse of 13 March 4BC and a too-near Passover (12 April 4 BC), by determining another date after studying all eclipses visible from Jerusalem in near years. This analysis-supported by a novel simulation of naked-eye visibility of partial lunar eclipses-has shown that the most eligible eclipse associable to Herod's death occurred in the night of 8-9 November 2 AD. Besides this astronomical finding, our conclusion is also supported by significant correlation between segmented sleep and eclipse intervals; by its compatibility with the long sequence of events narrated by Josephus and with the rabbinic tradition about Herod's death. This dating also agrees with other historical facts connected to Roman and Jewish history. In conclusion, Herod the Great must have died in the first month of $3 \mathrm{AD}$ and, very likely, Dionysius Exiguus was correct.
\end{abstract}

Keywords: Herod the Great's death date; Christian era beginning; segmented (bi-phase) sleep; lunar eclipse visibility; naked-eye vision

\section{A Slippery Dating}

On Jesus Christ's birth year, namely 1 BC (Before Christ), according to Dionysius Exiguus [1-12], who first, in the year $525 \mathrm{AD}$ (Anno Domini), proposed to count the years after his birth, there is a long-lasting patristic tradition that has been considered correct for centuries. However, after E. Schürer [13,14], at the end of the XIX century, many scholars have changed their opinion on its correctness and have researched another date, starting from two major events. The first is the so-called "slaughter of the innocents," before $2 \mathrm{AD}$, ordered by Herod the Great for killing the infant Jesus, according to Matthew (Mt 2.1 and following), therefore implying that Herod was still alive after Jesus' birth. The second event is the lunar eclipse observed in Jerusalem just before Herod's death, as Josephus writes (for Herod's last days see Josephus, Jewish War = BJ I. 647-673; II. 1-13; Jewish Antiquities = AJ XVII. 146-199. The lunar eclipse is specifically mentioned in AJ XVII. 167). Schürer, a theologian, looking into the astronomical almanacs, found a lunar eclipse visible from Jerusalem in March 4 BC. From this eclipse, and from other historical considerations concerning the duration and end of the reigns of Herod's three sons, he concluded that Herod died in 4 BC. Today, most scholars [13-16] set Jesus Christ's birth in the year 5 BC, while Dionysius Exiguus' 1 BC date is referred to as the "conventional" date of the Christian era beginning.

There are, however, several reasons against setting Herod's death in 4 BC. 
Josephus was not Herod's contemporaneous. His source of information was the work of the Jewish historian Nicolaus Damascenus, Herod's intimate friend, in which Josephus, very likely, read about the lunar eclipse which occurred just before Herod's death.

An issue poorly discussed is whether the lunar eclipse associated with Herod's death was visible with naked eyes, the only way, of course, of observing it. The 4 BC eclipse was partial and with a low umbral magnitude, about 0.36 , very difficult to observe with naked eyes according to the long-lasting personal experience of a modern professional astronomer [17]. Moreover, this eclipse occurred deep in the middle of the night, therefore questioning the sample size of people who might have observed and recognized the phenomenon. In ancient societies, long before electrical illumination, most people slept according to the so-called segmented sleep $[18,19]$, namely a nightly sleep divided in two parts and seasonally dependent, which could start two to three hours after sunset, with a waking-up interval around midnight. As well, in the Bible [20] there are several possible references to segmented sleep.

In Jerusalem there were professional observers of the Temple, whose duty was to establish, just after sunset, the new Moon for fixing the beginning of a new month of the Jewish luni-solar calendar. This information was fundamental because it served to fix the date of very important pilgrimages to Jerusalem, which occurred in full Moons, as Paul of Tarsus (Ep. Col. 2, 16) also recalls. Jewish months lasted 29 or 30 days [16], by convention.

The date proposed by Schürer raised objections already in the XIX century, including by C. E. Caspari [21], who has been recently recalled by historians [22-24]. Doubts arise because the events narrated by Josephus in Jewish Antiquities are too many to have occurred in 29 days only, which is the interval between the lunar eclipse on 13 March $4 \mathrm{BC}$ and the following Passover on April 12. A. E. Steinmann [24] has calculated that the sequence of these events, to be credible, must have taken at least 41 consecutive days. $\mathrm{He}$ also recalls that other scholars have even estimated longer intervals: 54 days by $\mathrm{E}$. L. Martin [24-26] and more than 60 days by T. D. Barnes [14,24]. Therefore, a minimum interval of 1.5 2 months between the eclipse and the following Passover is a fundamental and unavoidable constraint in establishing the year of Herod's death. In other words, these scholars conclude Josephus did not refer to the eclipse of $4 \mathrm{BC}$.

The purpose of this paper is to reconsider all chronological, historical and astronomical elements which, directly or indirectly, can be referred to Herod's death and determines its year. This affects, of course, the year of Jesus's birth and the beginning of the Christian era.

In Section 2, we summarize the knowledge on the eclipse associated with Herod's Death and discuss the topic with a new approach based on the effective visibility with naked eyes of these astronomical events. To this purpose, in Appendix A, we report, at length, our original physical-mathematical analysis of how partial eclipses with low umbral magnitude are seen with naked eyes. In Section 3, we discuss the correlation between segmented sleep and time of eclipses for estimating how likely it is that the eclipse was observed by people. In Section 4, we consider further historical constraints on Herod's death dating because of Jewish history and rabbinic tradition. In Section 5, we discuss the chronological constraints associated with Herod's death. Finally, in Section 6, we conclude by proposing, as correct, the dating of the beginning of the Christian era fixed by Dionysius Exiguus in the VI century.

\section{The Search of the Eclipse Associated with Herod's Death}

Herod died (Josephus, AJ XVII. 167; 191; 213) after a lunar eclipse and before Passover. From astronomical calculations, there was a partial eclipse in the first hours of 13 March $4 \mathrm{BC}$. Because the reigns of Herod's sons, under some specific assumptions, started in 4 BC- - a topic we discuss in detail in Section 5. Starting from Schürer's work [13], many scholars have concluded that Herod died in 4 BC. Therefore, Dionysius Exiguus was wrong in calculating the beginning of the Christian Era—by four years at least—because Herod must have been alive when Jesus was born $(M t 2)$. 
For solving the apparent incompatibility of the historical facts narrated by Josephus with the date of the eclipse and a too-near Passover, a first step is to determine an alternative date to $4 \mathrm{BC}$ by examining other eclipses of near years. This research has been partially done by several scholars [14-16,22,27-29] who, however, have only deepened their motivation to accept a particular eclipse. They did not study and compare the several eclipses that occurred across the beginning of the Christian era, except for one recent work [30].

Not all lunar eclipses are equally visible. At the Earth's distance, the Sun is seen under an angle of $0.5^{\circ}$, which causes the Earth to produce the umbra shown in Figure 1. Eclipses can be total, partial or penumbral, according to the Moon's position in the obstructed cone. Moreover, because of diffusion and diffraction phenomena in the Earth's atmosphere, some sunlight is partially scattered also in the umbra so that the Moon is still visible even in total eclipse, although it is much less luminous than in full Moon, and assumes the typical reddish color, as schematized in Figure 1.

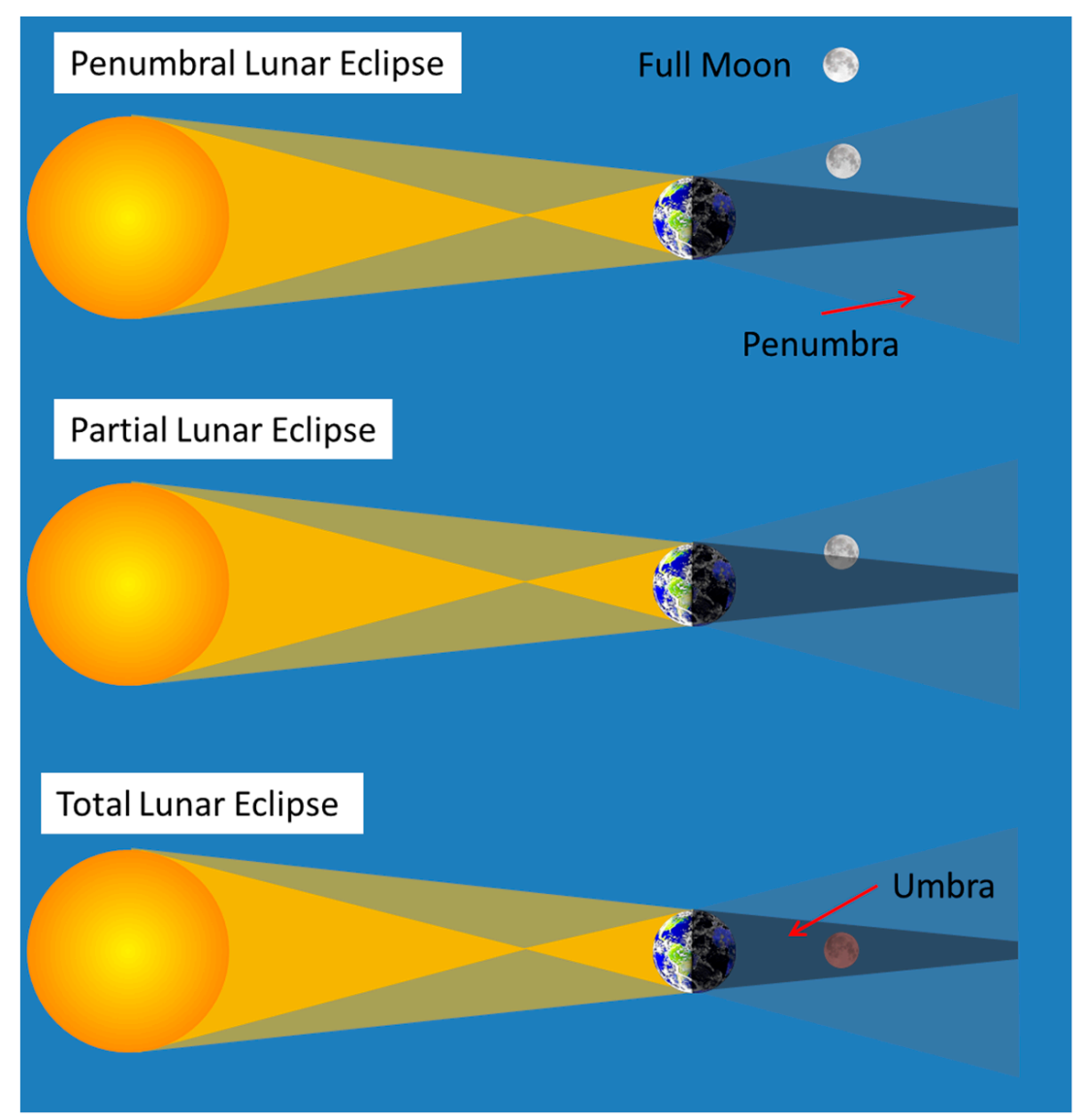

Figure 1. Penumbral, partial and total lunar eclipses.

Since Schürer [13], thanks to Schaefer [31,32], now we know many elements which affect the naked-eye visibility of a lunar eclipse: local atmospheric conditions, hour, elevation angle of the Moon under which it seen at a site and percentage of lunar dish shadowed in the eclipse. Therefore, in this section, we compare several eclipses cited by historians to verify - with modern software programs - their compatibility with the date of Passover following the eclipse and with other chronological constraints derived by Josephus. All dates reported in the following are due to astronomical calculations done with the software Skychart, developed by Patrick Chevalley (http:/ /www.ap--i.net/skychart/ accessed on 11 December 2019), and from the NASA database (http: / / eclipse.gsfc.nasa.gov / accessed on 12 May 2021) and calculations done by Fred Espenak, based on an algorithm developed by Meeus [33], made available to scholars for historical research. With this regard, it should be stressed that scholars and astronomers have considered only partial/total umbral lunar 
eclipses because penumbral eclipses are hardly recognizable with a naked-eye vision, as it will be clear after the quantitative analysis of the visibility of partial Moon's eclipses discussed in this study.

The eclipses associable to Herod's death are reported chronologically in the following list:

(1) 15 September $5 \mathrm{BC}$, proposed by Barnes [14];

(2) 13 March $4 \mathrm{BC}$; "classic" date indicated by historians, first proposed by Schürer [13];

(3) 10 January $1 \mathrm{BC}$, by Filmer [27];

(4) 29 December 1 BC, by Pratt [22];

(5) 8-9 Novembre 2 AD, by Fedalto $[11,29,34]$.

Table 1 reports the main characteristics of these eclipses.

Table 1. Lunar eclipses associable to Herod's death. Time and elevation angle refer to maximum eclipse visibility (half eclipse duration), except for the eclipse indicated by Pratt, not visible from Jerusalem at its maximum visibility because the Moon has not yet risen.

\begin{tabular}{|c|c|c|c|c|c|}
\hline Author & Barnes & Schürer & Filmer & Pratt $\left(^{*}\right)$ & Fedalto \\
\hline Eclipse date & 15 September 5 BC & 13 March 4 BC & 10 January 1 BC & 29 December 1 BC & $\begin{array}{c}\text { 8-9 November } \\
2 \text { AD }\end{array}$ \\
\hline $\begin{array}{c}\text { Maximum fraction } \\
\text { of lunar dish } \\
\text { shadowed }(\%)\end{array}$ & 100 & 36 & 100 & 57 & 46 \\
\hline $\begin{array}{l}\text { Time of maximum } \\
\text { fraction }\end{array}$ & $22: 12$ & 02:41 & 01:09 & $16: 30(*)$ & $00: 43$ \\
\hline $\begin{array}{c}\text { Moon elevation } \\
\text { angle at maximum } \\
\text { fraction }\end{array}$ & $54^{\circ}$ & $40^{\circ}$ & $70^{\circ}$ & $<0^{\circ}\left({ }^{*}\right)$ & $67^{\circ}$ \\
\hline $\begin{array}{l}\text { Approximate } \\
\text { eclipse duration }\end{array}$ & 20:20-24:00 & 01:30-03:50 & 00:20-03:00 & $16: 50-17: 50$ & 23:30-02:00 \\
\hline $\begin{array}{l}\text { Next } 15 \text { Nisan } \\
\text { (Passover) }\end{array}$ & 12 Apr 4 BC & 12 Apr 4 BC & 9 Apr 1 BC & 30 Mar 1 AD & 7 Apr 3 AD \\
\hline $\begin{array}{l}\text { Interval between } \\
\text { eclipse and } \\
\text { Passover (months) }\end{array}$ & 7 & 1 & 3 & 3 & 5 \\
\hline
\end{tabular}

$\left(^{*}\right)$ Not visible in Jerusalem when maximum, but only after Moonrise at 17:00.

Another eclipse, not reported in Table 1, occurred on 23 March 5 BC. It was total and well visible from Jerusalem. In Section 5, we discuss why it was not considered by Schürer and other proposers of 4 BC as the year of Herod's death.

\subsection{The Eclipse of $4 B C$ and Its Naked-Eye Visibility}

The partial eclipse indicated by Schürer occurred on 13 March 4 BC, started at 01:30, had the lowest fraction of shadowed lunar surface $(36 \%)$, reached its maximum umbral magnitude at 2:40, with elevation angle $40^{\circ}$ and ended at 03:50, with the Moon seen with $26^{\circ}$ elevation angle. However, when only about a third of the lunar surface is shadowed by the Earth, as happened during this eclipse when it reached its maximum umbral magnitude, the Moon appears almost as a full Moon not yet completed [17], because only a very small border region of the dish seems to be missing. This visual effect is the consequence of the non-linearity of the naked-eye visual system, as discussed in detail in Appendix A. This characteristic of human vision is also at the base of the traditional scale of six magnitudes describing the brightness of stars visible with naked eyes. Notice, however, that, because of the non-linear response, even if a star of first magnitude is 100 times more luminous than a star of sixth magnitude, it appears as being only five times (magnitudes) brighter. This non-linear rescaling is just described by the magnitude scale, and is an important feature of the human visual system, as discussed at length in Appendix A. 
In Figure 2, we show how the eclipse of 4 BC would have been seen with naked eyes from Jerusalem (see Appendix A for further details).

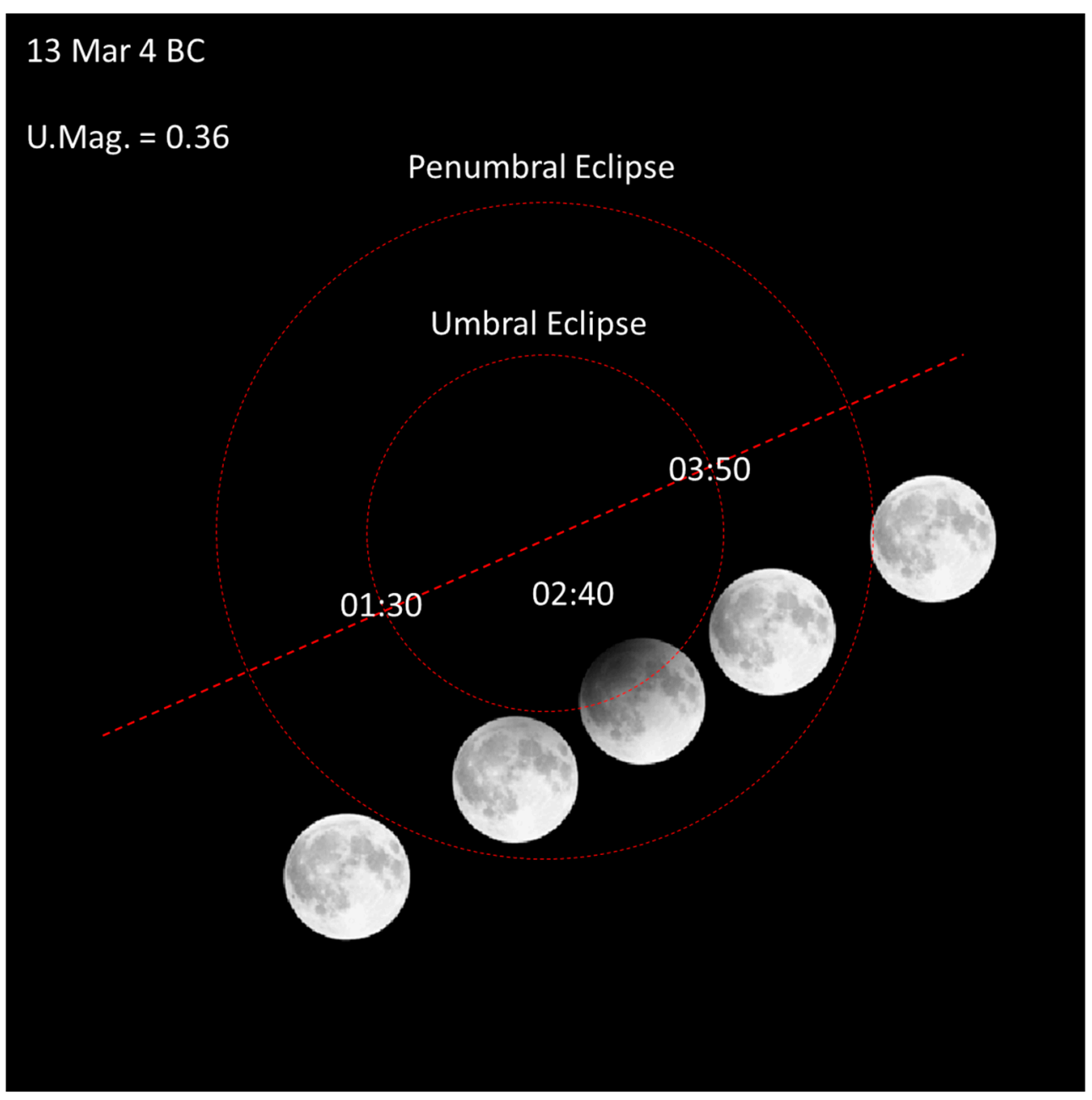

Figure 2. Simulation of the partial eclipse as it would be seen with a naked-eyes vision from Jerusalem on 13 March 4 BC, associated by Schürer with Herod's death. The eclipse started at 01:30, reached its maximum umbral magnitude at 02:40 and ended at 03:50.

The two circles of Figure 2 indicate the regions of umbra (innermost circle, produced by the shadow of the Earth, see Figure 1) and penumbra (outmost circle, see also Figure 1). In Figure 2, one pixel corresponds to 21 " of degree. This value corresponds to half of the angular resolution of the average human eye, 42", for typical lunar [35] surface brightness. The diameter of the Earth's shadow-innermost circle-is about 2.67 of the Moon diameter.

The Moon shown in the central part of the sequence is in the umbra (innermost circle) during the maximum eclipse umbral magnitude, while the Moon shown just to the left and to the right is in the penumbra (outmost circle). Finally, the Moon shown outside the penumbra is a full Moon. As is possible to notice in Figure 2, the penumbral eclipses do not show appreciable brightness variations, if compared to a full Moon, because of the non-linear compression of perceived light intensities. Even in the maximum phase, the partial eclipse (central position) would have not been actually noticeable. As already observed by the astronomer Nollet [17], only a very small border region appears to be eroded. Very likely, to an occasional observer of 2000 years ago, in the middle of the night, the Moon would have appeared as a full Moon.

Finally, we recall that this eclipse was too near the following Passover (one month) to allow all the events narrated by Josephus to occur. Therefore, because of small umbral magnitude $(36 \%)$, the time of the day (middle of the night)-issue discussed also in 
Section 3-and chronological events, this eclipse should not be associated with Herod's death as is currently done by most scholars.

\subsection{The Eclipses of $5 B C$}

Because the eclipse of 4 BC was too near to Passover, Barnes [14] associated Herod's death with the total eclipse that occurred on 15 September 5 BC, however, most scholars do not agree because this day is seven months from Passover, too remote and is even before the Feast of Tabernacles and the day of fast Yom Kippur, which occurs a few days before the Tabernacles, an issue discussed in Section 4. Josephus would have noticed that the eclipse, associated with Herod's death, had occurred before Tabernacles, not before Passover. This eclipse was visible from Jerusalem, in the total phase, from 21:20 to 23:00, while, including its partial phase, it was visible from 20:20 to 24:00, when the Moon reached the maximum elevation angle of $54^{\circ}$.

On 23 March 5 BC, another (total) eclipse occurred, visible from Jerusalem, however, as for the eclipse of $4 \mathrm{BC}$, it is very near Passover to allow all facts narrated by Josephus after Herod's death. Notice that NASA (Web sites: https:/ / eclipse.gsfc.nasa.gov/LEhistory/ LEhistory.html; https:/ / eclipse.gsfc.nasa.gov/LEhistory /LEplot/LE--0004Mar23T.pdf, accessed on 29 April 2021) no longer associates the eclipse of 4 BC with Herod's death, but indicates the total eclipse occurred on 23 March 5 BC. However, as we discuss in Section 5, this eclipse also cannot be that mentioned by Josephus.

In other words, the lunar eclipses eligible to be that mentioned by Josephus are those occurring between Tabernacles and Passover, but about two months before Passover and not before $4 \mathrm{BC}$. Therefore, if we exclude the eclipses of $5 \mathrm{BC}$ and $4 \mathrm{BC}$, only the eclipses across the beginning of the Christian era are left (Table 1).

\subsection{The Eclipses of $1 B C$}

The total eclipse on 10 January 1 BC (Filmer) was visible from Jerusalem and occurred in the middle of the night, from 00:20 to 02:00. The partial phase ended at about 03:00, with the Moon seen at $48^{\circ}$. As it was total, this eclipse would have been noticed, undoubtedly, by anyone awake, with none of the problems discussed in Appendix A. However, in Section 5, we will discuss its incompatibility with some historical events and consequent constraints.

Another partial eclipse occurred on 29 December 1 BC (Pratt). It started at 16:30 and theoretically could have been visible from Jerusalem as soon as the Moon rose, when many people were still awake and active, and therefore be noticed more than the other eclipses listed in Table 1. However, the eclipse reached the maximum umbral magnitude of $57 \%$ at 16:30 but the Moon was not visible from Jerusalem because it had not yet risen. It ended at 17:48 when the Moon was at only $11^{\circ}$ above the horizon and a fraction shadowed, at only $25 \%$.

The Moon rose at $26^{\circ}$ North of the East direction, behind the Mount of Olives, which is about $100 \mathrm{~m}$ higher than the mean altitude of Jerusalem, therefore it was hidden at the beginning. Moreover, as the sunset occurred at about 17:10, the eclipse was not clearly visible for at least $20 \mathrm{~min}$, because of twilight coming from West. Indeed, according to Schaefer [31], partial eclipses with the lunar disc shadowed up to $50 \%$ are visible only when the Moon elevation angle is above $3.5^{\circ}$. Therefore, this eclipse would have been visible only after 17:30, when the twilight had diminished enough, with a partial shadowing close to $25 \%$, smaller than that characterizing the partial lunar eclipse of $4 \mathrm{BC}$. In conclusion, of the two eclipses that occurred in $1 \mathrm{BC}$, the only one associable to Herod's death is the total eclipse that occurred on 10 January; however, it is discarded in Section 5.

\subsection{The Eclipse of $2 A D$ and Conclusions}

The partial eclipse that occurred in the night 8-9 November 2 AD was visible in Jerusalem from 23:30 to 02:00. At 0:43, the eclipse reached its maximum fraction of $46 \%$ with the Moon seen at $67^{\circ}$, the highest elevation angle of the five eclipses analyzed in 
this study, therefore the most visible in Jerusalem's mountainous area. This is the eclipse associated with Herod's death by Fedalto [11,29,34].

In Figure 3, as done in Figure 2, we show the simulation of how brightn this eclipse would have been seen with naked eyes. The Moon appears eroded near the border, a phenomenon clearly visible, different to what is shown in Figure 2, therefore very likely recognizable as an astronomical event by occasional observers. Indeed, the Moon shows a shadowed border with a concave profile, typical of the projection of the Earth's umbra. Instead, in the eclipse of $4 \mathrm{BC}$, the shadowed profile is convex, more similar to what is seen when a full Moon is not yet completed.

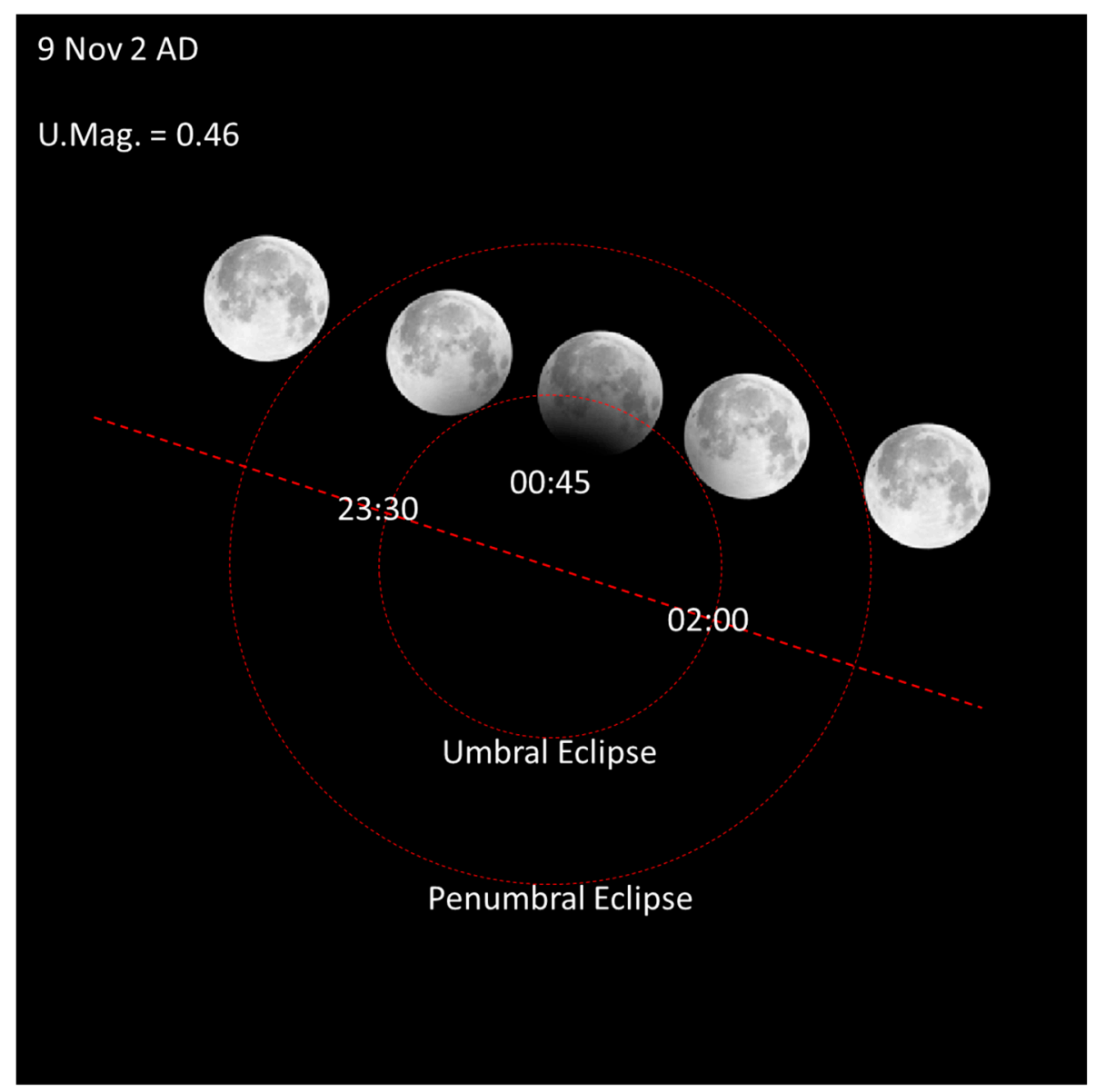

Figure 3. Simulation of the partial eclipse as it would be seen with a naked-eyes' vision from Jerusalem in the night 8-9 November 2 AD, associated by Fedalto with Herod's death. The eclipse started at 23:30, reached its maximum at 00:45 and ended at 02:00.

Therefore, the eclipse of $4 \mathrm{BC}$, very likely, would have not been noted by occasional observers, differetly from the eclipse of $2 \mathrm{AD}$, as can be noted in Figure 4, where the two eclipses are compared for better appreciating their different visibility.

In conclusion, the eclipses more eligible to be associated with Herod's death are those that occurred on January $1 \mathrm{BC}$ and November $2 \mathrm{AD}$, not that which occurred in $4 \mathrm{BC}$, as is often currently assumed.

As most eclipses occurred during evening or night, it is useful to estimate how likely people were awake to possibly observe the Moon and recognize the phenomenon. In the next section, therefore, we discuss the so-called "segmented sleep". 


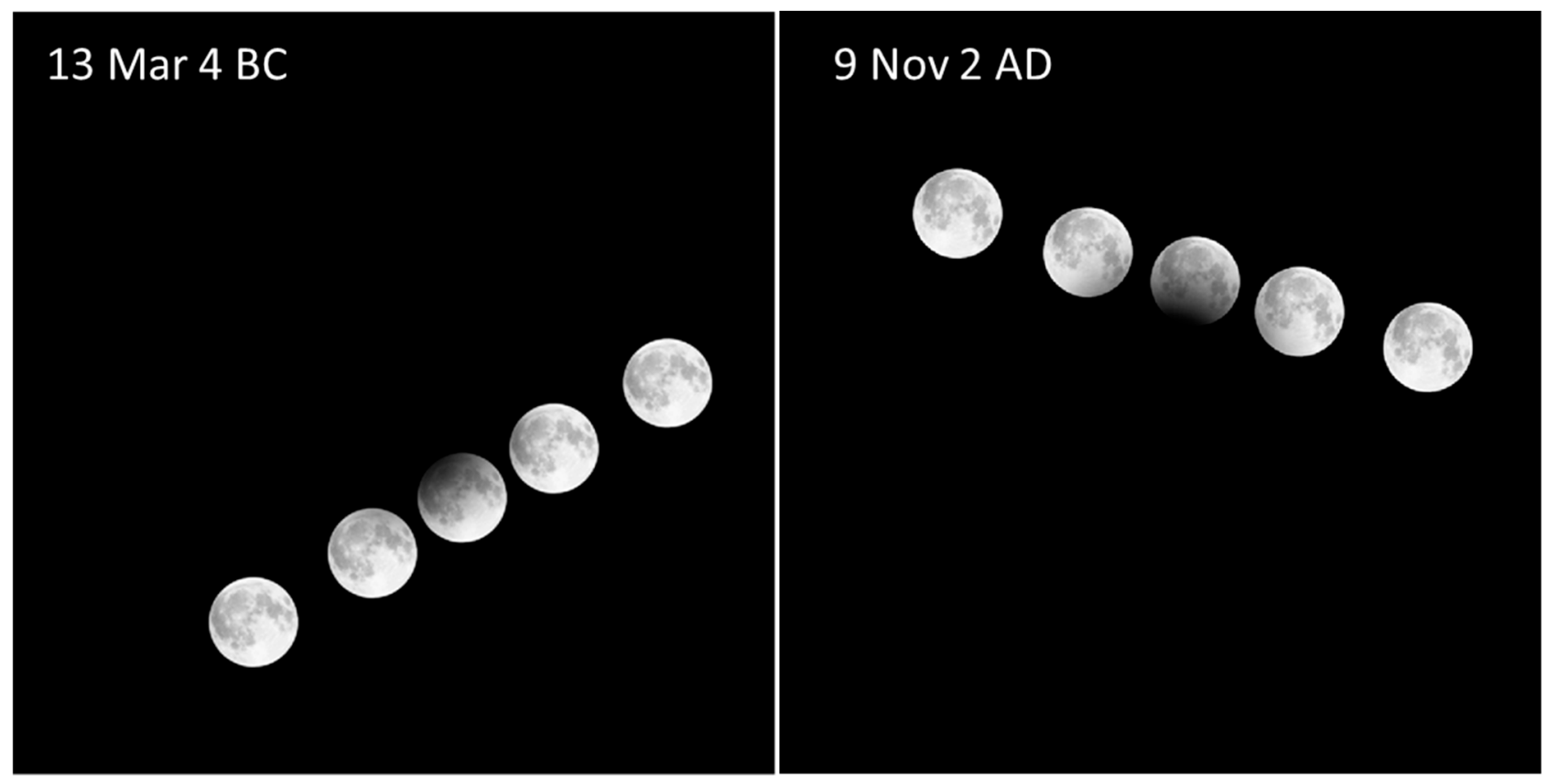

Figure 4. Comparison between the naked-eyes' vision of the eclipse that occurred on 13 March 4 BC (Schürer) and the eclipse that occurred in the night 8-9 November 2 AD (Fedalto).

\section{Correlation between Segmented-Sleep and Time of Eclipses}

Experiments [36] on volunteers kept in complete dark environment for intervals longer than $12 \mathrm{~h}$ have shown that bi-phase sleep (or segmented sleep, when referred to night sleep) is the most natural way of human sleep. Bi-phase sleep has been recently documented [37] in African people such the Tiv population in Nigeria. Recent studies [18] on ancient literary sources lead to the conclusion that segmented sleep was common not only in pre-industrial societies but also in the Roman Empire, i.e., in the Mediterranean world, therefore including Palestine.

Moreover, segmented sleep is also present in the Bible [20]. In the New Testament, some parables seem to refer to segmented sleep: at midnight someone could knock at a friend's door for borrowing three loaves of bread (Luke 11,5), or five girls could be invited to go to the store-in the middle of the night! - to buy some oil for their lamps (Mt 25, 9-10), or watchful servants, suitably dressed and with lamps lit, are waiting just at midnight, or before the sunset, for their master to come back from a wedding feast (Lk 12, 35-38). Jesus was arrested in the middle of the night, and part of the Sanhedrin readily gathered in the house of the High Priest to judge him, a reunion difficult to imagine in a society such as ours, where segmented sleep is not practiced. Paul and Silas, prisoners at Philippi, in the Roman colony of Macedonia, sing hymns to God at midnight. The other prisoners hear them singing but do not complain (Acts 16, 25). In the Old Testament there are many references to specific night activity, as in the Books of Judith $(11,17)$ and Samuel $(28,22)$, in psalms (e.g., Ps 119, 62).

Widespread customs of people of ancient epochs might not be fully understood, and maybe misunderstood, by people of other epochs-such as us- because many of these practices were abandoned a long time ago, such as, for example, the monastic rule of Benedictines, which appears to us very ascetic - they go to sleep at 20:00 and awake at midnight for prayers and so on. However, this custom is clearly tailored to the segmented sleep of their founder, Benedict [20] (p. 217), [38,39], of the VI century, a common practice at his time for most people. Therefore, it is reasonable to assume segmented sleep to be common in Palestine 2000 years ago, as in the rest of the Roman Empire. In other words, occasional potential observers of a noticeable eclipse should not have been few because people were awake and possibly active outdoors. 
Not all scholars [40] agree on widespread segmented sleep in the Roman society 2000 years ago. However, if we consider that artificial lighting [41], because of its cost, was available only to the richest people, and, on the average, a human being needs to sleep for a total of $7 \mathrm{~h}$ (in summer) and $8 \mathrm{~h}$ (in winter), it can be assumed that segmented sleep was practiced by most people.

In Palestine, autumn and winter months' nights last around $12 \mathrm{~h}$, therefore it is clear that most people could not sleep continuously for $12 \mathrm{~h}$ [42]. People would start sleeping $[18,43]$ about two hours after sunset. In these months, when the eclipses listed in Table 1 occurred, at the latitude of Jerusalem the sun rises between 6 and 7 and sets between 17 and 18. Night lasts from $11 \mathrm{~h}$ and $20 \mathrm{~min}$ to $12 \mathrm{~h}$ and $10 \mathrm{~min}$, therefore the largest variation is only one hour, and thus we can ignore it in observing the eclipses listed in Table 1 . Now, by assuming a two-hour $[18,43]$ interval between sunset and time of sleep, $10 \mathrm{~h}$ are left. Because in the autumn-winter months the daily average total time of sleep is about eight hours, it is reasonable to divide the segmented sleep time into two average intervals of four hours each, with two hours of possible activity in between, around midnight.

Table 2 reports the time and duration of the eclipses listed in Table 1 against the most likely intervals of segmented sleep. Eclipse times are approximated to the hour, with a maximum indetermination of a half hour: for example, 23:20 becomes 23 and 23:40 becomes 24:00. From Table 2, we notice the eclipses on 10 January BC (Filmer) and 2 AD (Fedalto) are the best suited to be observed by occasional observers because they largely overlap with the interval of possible activity in the segmented sleep. The eclipse on 29 December $1 \mathrm{BC}$ (Pratt) is around the sunset, therefore it could have been seen by many occasional observers; however, it lasted only few tens of minutes and had a very low percentage of lunar disc shadowed, therefore it might not have been recognized as an eclipse, as previously discussed. The eclipses of 5 BC (Barnes) and 4 BC (Schürer) occurred in sleep time for most people, therefore had a lower probability of being observed than the eclipses proposed by Filmer or Fedalto.

Table 2. Eclipse duration (light-gray cells = partial eclipse; dark-gray cells = total eclipse) against the most likely period of sleep, according to segmented sleep theory (dashed cells). The hours in green are those with high probability of finding occasional observers; the hours in red are those with low probability of finding occasional observers.

\begin{tabular}{|c|c|c|c|c|c|c|c|c|c|c|c|c|c|c|c|}
\hline Hour & 16 & $\begin{array}{l}\text { 17-18 } \\
\text { Sunset }\end{array}$ & 18 & 19 & 20 & 21 & 22 & 23 & 24 & 01 & 02 & 03 & 04 & 05 & $\begin{array}{l}\text { 06-07 } \\
\text { Sunrise }\end{array}$ \\
\hline $\begin{array}{c}5 \mathrm{BC} \\
\text { (Barnes) }\end{array}$ & & & & & & & & & & & & & & & \\
\hline $\begin{array}{c}4 \text { BC } \\
\text { (Schürer) }\end{array}$ & & & & & & & & & & & & & & & \\
\hline $\begin{array}{c}10 \text { January } 1 \text { BC } \\
\text { (Filmer) }\end{array}$ & & & & & & & & & & & & & & & \\
\hline $\begin{array}{c}29 \text { December } 1 \text { BC } \\
\text { (Prat) }\end{array}$ & & & & & & & & & & & & & & & \\
\hline $\begin{array}{c}2 \mathrm{AD} \\
\text { (Fedalto) }\end{array}$ & & & & & & & & & & & & & & & \\
\hline Sleep intervals & & & & & & & & & & & & & & & \\
\hline
\end{tabular}

Let us notice that if the sleep time is anticipated by one hour, i.e., it starts only one hour after sunset, the final result would not change significantly. On the other hand, if it is delayed by one hour, i.e., it starts three hours after sunset, the timing is not realistic in the autumn-winter months as is in the spring-summer months.

Although we cannot base our conclusion on cogent statistics, the correlation between the segmented sleep and eclipses' time intervals seems to indicate the eclipses proposed by Filmer or by Fedalto as the most eligible to be associated with Herod's death. Indeed, the difficulty to recognize the astronomical phenomenon by any occasional observer, due to 
naked-eye vision limitations, is already sufficient to disregard the lunar eclipse of $4 \mathrm{BC}$ as that mentioned by Josephus.

In the following sections, we will deepen other chronological constraints according to the facts narrated by Josephus.

\section{Constraints Due to Yom Kippur (the Day of Fast) and to Rabbinic Tradition}

From Josephus, we know that before the eclipse associated with Herod's death, the important day of Yom Kippur had just occurred. Indeed, Josephus (AJ XVII. 165-167) mentioned the impurity of the priest Matthias in a fasting day occurring some time before the lunar eclipse. Yom Kippur, on 10 Tishri, was not the only day of fast [30]. Josephus, however, refers to it as a single day (AJ XVII. 165-167), very likely because it was the most important day of fast.

In an attempt to reconcile this indication with the Josephus' chronology, Schwartz proposed $5 \mathrm{BC}$ as the year of Herod's death, as Barnes did, but anticipating the beginning of the liturgical year by one lunar month, so that the eclipse occurred on 15 September 5 BC, simultaneously with the feast of Tabernacles and just after Yom Kippur on 12-13 September [44] (pp. 157-166), [45].

Let us notice, however, that according to the chronology proposed by Parker and Dubberstein [46] (p. 45), Yom Kippur occurred a lunar month later than assumed by Schwartz. This is also the chronology assumed by Barnes, and also by us, because, otherwise, Passover of the year $5 \mathrm{BC}$ would have occurred just on the vernal equinox, which is impossible because of the constraint that on Passover the sun must have been in constellation of Aries, as explicitly mentioned by Josephus (AJ III. 248) [16]. As a proof, astronomical calculations concerning 2000 year ago show that, on the sunrise of 23 March 5 BC, whose evening would have started Passover (15 Nisan) according to Schwartz, the sun rose in the constellation of Pisces, not Aries [47].

Moreover, the book Megillat Ta'anit, written just after the destruction of the Temple in $70 \mathrm{AD}$, reports that Herod died on 7 Kislev or 2 Shevat, because in these days fasting was not allowed (Megillat Ta'anit, 23), without explaining why, very likely because the reason was well known to contemporary readers [27,48]. Only across the VII and VIII centuries, some rabbinic commentators clarify that fasting was prohibited because that day was a festive day referred to Herod's death (Josephus, BJ I. 660)_-just to evidence how Herod was disliked-and that he died on $7 \mathrm{Kislev}$, although many scholars have proposed 2 Shevat [49] (p. 347), [27].

In summary, by considering all these indications and the chronology due to Josephus, Yom Kippur and the day of the eclipse should not be separated by too long an interval, because the events between these two days are narrated by Josephus (AJ XVII. 165-167) in a short sequence. On the contrary, in the interval between the eclipse and Passover, Josephus reports many events narrated in many chapters (AJ XVII. 167-213). Therefore, the chronological sequence of events should be the following:

(1) Yom Kippur (10 Tishri);

(2) Eclipse (closer to Yom Kippur than to Passover);

(3) Herod's death (7 Kislev or 2 Shevat);

(4) Passover (15 Nisan).

For a synoptic view of all chronological and historical constraints, Table 3 reports the dates of Yom Kippur, eclipses, Herod's death according to the rabbinic tradition and Passover, following the sequence of events described by Josephus and comparing it with what is deducible from Megillat Ta'anit, 23. We have reconstructed the Jewish calendar by imposing that at least $2 \%$ of the lunar disc $[30,50]$ was already illuminated after sunset, to be visible by the Sahnedrin's observers, set to establishing the beginning of a new lunar month. We do not know the years considered embolismic in the Jewish luni-solar calendar because the liturgy on 16 Nisan planned the offer of the first sheaves of ripe barley/wheat to the Temple, and this depended on winter weather, causing the introduction of a second month of Adar only when needed. In any case, in the calculations summarized in Table 3, 
we have introduced a thirteenth month in the ending year, every time the first full Moon occurred within 3-4 days after the equinox (23 March), because according to the ancient rule recorded by Josephus ( $A J$ III. 248), the sun rose in the constellation of Aries only after 27 March.

Table 3. Chronological sequence of ritual day Yom Kippur, Passover (which started at sunset of the day before that indicated in the lower line), lunar eclipse associated to Herod's death. "E" stands for embolismic year. Red (green) color indicates incorrect (correct) sequence and the interval of the eclipse with Yom Kippur and Passover.

\begin{tabular}{|c|c|c|c|c|c|}
\hline Author & Barnes & Schürer & Filmer & Pratt & Fedalto \\
\hline Year & $5-4 \mathrm{BC}$ & $5-4 \mathrm{BC}$ & $2-1 B C$ & $1 \mathrm{AC}-1 \mathrm{AD}$ & $2-3 \mathrm{AD}$ \\
\hline & $\begin{array}{c}\text { Eclipse } \\
15 \text { September } 5 \text { BC }\end{array}$ & & & & \\
\hline $\begin{array}{l}10 \text { Tishri } \\
\text { (Fast day) }\end{array}$ & $\begin{array}{c}13 \text { October } \\
5 \mathrm{BC}\end{array}$ & $\begin{array}{l}13 \text { October } \\
5 \mathrm{BC}\end{array}$ & $\begin{array}{l}10 \text { October } \\
2 \mathrm{BC}\end{array}$ & $\begin{array}{c}28 \text { September } \\
1 \mathrm{BC}\end{array}$ & $\begin{array}{l}5 \text { October } \\
2 \mathrm{AD}, \mathrm{E}\end{array}$ \\
\hline & & & & & $\begin{array}{c}\text { Eclipse } \\
\text { 8-9 November } \\
2 \text { AD }\end{array}$ \\
\hline \multirow[t]{2}{*}{$\begin{array}{c}7 \text { Kislev } \\
\text { (Herod's death } \\
\text { day) } \\
\end{array}$} & $\begin{array}{c}6 \text { December } \\
5 \mathrm{BC}, \mathrm{E}\end{array}$ & & & & $\begin{array}{c}1 \text { December } 2 \mathrm{AD} \\
\mathrm{E}\end{array}$ \\
\hline & & & $\begin{array}{c}\text { Eclipse } \\
10 \text { January } \\
1 \mathrm{BC} \\
\end{array}$ & $\begin{array}{c}\text { Eclipse } \\
29 \text { December } 1 \text { BC }\end{array}$ & \\
\hline $\begin{array}{c}2 \text { Shevat } \\
\text { (Herod's death } \\
\text { day) }\end{array}$ & & & $\begin{array}{l}28 \text { January } \\
1 \mathrm{BC}, \mathrm{E}\end{array}$ & $\begin{array}{l}16 \text { January } \\
1 \mathrm{AD}\end{array}$ & $\begin{array}{l}24 \text { January } \\
3 \mathrm{AD}, \mathrm{E}\end{array}$ \\
\hline & & $\begin{array}{c}\text { Eclipse } \\
13 \text { March } \\
4 \mathrm{BC} \\
\end{array}$ & & & \\
\hline $\begin{array}{l}15 \text { Nisan } \\
\text { (Passower) }\end{array}$ & 12 April 4 BC & 12 April 4 BC & 9 April 1 BC & $\begin{array}{l}30 \text { March } \\
1 \text { AD }\end{array}$ & $\begin{array}{l}7 \text { April } \\
3 \text { AD }\end{array}$ \\
\hline
\end{tabular}

In Table 3, we observe that the ritual day of Yom Kippur (10 Tishri) occurs:

(a) After the eclipse proposed by Barnes, therefore, as already noticed, it does not satisfy the chronological sequence due to Josephus;

(b) five months before the eclipse proposed by Schürer;

(c) three months before the eclipses proposed by Filmer and Pratt;

(d) Only 34 days before the eclipse proposed by Fedalto.

Therefore, of these five choices, only that proposed by Fedalto is very near 10 Tishri, only about a month later, in agreement with the temporary substitution of the high priest on Yom Kippur, a fact (Josephus, AJ XVII. 165-167) [2,30,45] that should have happened not too long before the eclipse.

For the day of Herod's death, from Barnes, we obtain 6 December 5 BC (7 Kislev), which allows for enough time before Passover, although there is the problem that the eclipse occurred in a day before Yom Kippur. The date of Herod's death proposed by Schürer cannot agree with the rabbinic tradition (deducible from Megillat Ta'anit, 23) because both 2 Shevat and 7 Kislev occur before the eclipse.

In both Filmer's and Pratt's proposals, 2 Shevat occurs 18 days after the eclipse. Seven Kislev is excluded because it is about two months before 2 Shevat and, thus, before the eclipse. Therefore, if the eclipse was one of the two of $1 \mathrm{BC}$, only $7 \mathrm{Kislev}$ is allowed as the day of Herod's death. For the same reasons, the eclipse of 4 BC and those of 1 BC must all be excluded because, in the latter case, the interval of 18 days between the eclipse and 2 Shevat, Herod's death, is too short for all facts narrated by Josephus. In other words, the lunar eclipse in 1 BC would imply that the rabbinic tradition about the day of Herod's death were wrong. 
Finally, for the eclipse of November 2 AD proposed by Fedalto, the day 7 Kislev would be about three weeks after the eclipse, on 1 December; while 2 Shevat would be on 24 January 3 AD, giving enough time (more than two months) for the events narrated by Josephus. Therefore, the eclipse of November 2 AD is the only one compatible: (a) with the long sequence of events narrated by Josephus; (b) with the rabbinic tradition about Herod's death; (c) with the astronomical constraints.

\section{Chronology Issues Concerning Herod's Death}

There are some historical constraints which must be harmonized with the astronomical constraints, so that we can establish a coherent picture of all the information provided by Josephus about Herod's death, in agreement with Roman and Jewish history.

\subsection{Inconsistency of the Year $4 B C$ and Earlier Years}

Josephus writes that Herod was declared king by the Romans in the year of the 184th Olympiad (Josephus, AJ XIV. 389), he reigned for 37 years since he was declared king and 34 years (Josephus, AJ XVII. 191) since Antigonus' death. Now, the 184th Olympic Games started in July 41 BC and finished in July 40 BC; however, Josephus indicates also the consuls of the year and this constraint indicates December $40 \mathrm{BC}$, not July. Elsewhere (Josephus, AJ XIV. 487-488), he writes that Herod conquered Jerusalem 27 years after Pompey conquered Palestine [51], which occurred in the year 63 BC, therefore, Herod would have conquered Jerusalem in the year $36 \mathrm{BC},(36=63-37)$, not in $37 \mathrm{BC}$ [51], which is the year usually indicated by scholars. Therefore, the historical constraints given by Josephus are self-consistent within one year of indeterminacy.

If we assume the beginning of spring 4 BC as Herod's death, since December 40 BC we count 35 years and 3 months of reign, 2 years fewer than the 37 indicated by Josephus. Similarly, since Jerusalem's conquest-beginning in autumn 37 BC and lasting to the Spring $4 \mathrm{BC}$ - there are 32 years and 6 months, not the 34 indicated by Josephus. Therefore, in both cases, there is a negative difference of about two years, which would set Herod's death in 3 or 2 BC. However, in these years, there were no eclipses visible from Palestine. This is the main problem that Schürer and later historians had to face. At the end of his investigation, Schürer opted for the nearest eclipse of 4 BC, by adding ad-hoc hypotheses. Let us review his ad-hoc hypotheses, according to Filmer [27]:

(1) Josephus applied the rule of the year of non-accession;

(2) The year started in the first day of Nisan;

(3) Herod died after the first day of Nisan;

These are ad-hoc hypotheses because only in this way can the few days between the first day of Nisan 4 BC and Herod's death before Passover (15 Nisan) be counted as a supplementary full year and can everything agree with the 37 and 34 years of reign indicated by Josephus. Now, it is clear why the eclipse on 23 March 5 BC was not considered by Schürer and other historians, because anticipating Herod's death by one more year would never agree with 37 and 34 years of reign, even with the above ad-hoc hypotheses [14].

\subsection{Historical Inconsistency of the Year 1 BC}

Because of these arguments, Filmer abandoned the year 4 BC by dating Jerusalem's conquest at the end of summer or beginning of autumn of the year 36 BC (Josephus, $A J$ XIV. 487-488), and, by adopting the rule of the year of accession, concluded that Herod's reign lasted 34 years and finished in $1 \mathrm{BC}$.

However, also this result, as observed by Firpo [15], is based on ad-hoc hypotheses to pass from $4 \mathrm{BC}$ to $1 \mathrm{BC}$. As there were no visible eclipses from Palestine in the years 3 and 2 BC, Filmer, to gain two years, to reach 1 BC, delayed Jerusalem's conquest from $37 \mathrm{BC}$ to $36 \mathrm{BC}$, and used the annual calendar starting in the first day of Tishri (the so-called Autumn calendar) [44] (p. 91) with the rule of accession. Only in this way can the year $1 \mathrm{BC}$ be reached after 34 years, overcoming the period without eclipses. However, Filmer's solution of $1 \mathrm{BC}$ does not agree with some historical constraints. For example, the dating of 
the Battle of Actium, that Josephus (AJ XV. 121) sets in the seventh year of Herod's reign. We know that this battle occurred on 2 September $31 \mathrm{BC}$; however, if we set the beginning of Herod's reign in $36 \mathrm{BC}$ and use the rule of the year of accession, the years to the Battle of Azio would be 4 not 7 .

In summary, Firpo criticizes Filmer because:

(1) Josephus did not apply the rule of the year of accession; the fraction of the year between Herod's conquest of power and the first day of the next year must be counted as first year of reign [15];

(2) By comparing Roman history and Josephus' writing on the arrival of August in Syria, the spring calendar (beginning the first day of Nisan) must be preferred [15] to the autumn calendar (first day of Tishri) adopted by Filmer.

\subsection{Hypothesis on the Period of Coregency of Herod and His Sons}

After the preceding observations, we suggest the following reconstruction:

(1) Herod did not die 34 years since Jerusalem's conquest, or 37 years since he was proclaimed king;

(2) After this time, the period of coregency with his three sons started;

(3) The beginning of coregency did not coincide with Herod's death; therefore, it must not necessarily have occurred in a year of an eclipse visible from Palestine.

Fedalto has strongly adopted the thesis of coregency [24] for explaining the chronological issues summarized above [29], although the coregency is not mentioned by Josephus. Supposedly, Herod would have abdicated the throne in favor of his three sons because of health problems, therefore applying the institution of coregency, as some predecessors had done, including Herod's father (Josephus, BJ I. 209) in his favor (Josephus, BJ I. 625; 631-632; AJ XVII. 2) [24]. Josephus would not have mentioned explicitly the period of coregency because it is not clearly stated in his historical sources as it occurred de facto not de jure [24]. Moreover, Strabo (XVI. 2, 46), who unlike Josephus was Herod's contemporary, explicitly writes that Herod had already assigned parts of his reign to his sons when he was still alive. This represents an important historical trace about the coregency which is missing in Josephus' writings.

Now, if we add the interval of 27 years since Pompey's conquest in $63 \mathrm{BC}$-to arrive at the beginning of Herod's reign - to 34 years of his reign, which would be the period of reign without coregency, we obtain 61 years. Counting the years with the inclusive modality, we arrive at $3 \mathrm{BC}$. This year could be the beginning of coregency. Indeed, by counting the years with the inclusive modality, Herod's son Philip, tetrarch of Iturea, died in the 20th year of Tiberius reign (August $33 \mathrm{AD}$ to $34 \mathrm{AD}$ ), after 37 years of reign. Therefore, his reign started in 3 BC. The exile of Herod's son Herod Archelaus, etnarch of Judea, Samaria and Idumea, is dated in $6 \mathrm{AD}$, after a reign of nine years (Josephus, $B J$ II. 111-113), or 10 years (Josephus, AJ XVII. 342), which always indicates the beginning of the reign to be $4 \sim 3 \mathrm{BC}$. The other son, Herod Antipas, tetrarch of Perea and Galilee, was exiled in 39 40 AD, after 43 years; therefore [11,51], his reign started in $3 \mathrm{BC}$. In conclusion, all the chronological data reported by Josephus converge to the year $3 \mathrm{BC}$ as the start of the regency of the three sons, which could be the beginning of coregency.

Therefore, for counting the years of reign, we can refer only to some of the Schürer's [27] hypotheses, those which share a widespread consensus among scholars [15]:

(1) Josephus applied the rule of non-accession;

(2) A year starts at the first day of Nisan.

The two hypotheses imply the 34th of Herod's extending form the first day of Nisan of $4 \mathrm{BC}$ to the end of Adar $3 \mathrm{BC}$. However, we have to renounce to Schürer's third ad-hoc hypothesis [27]-i.e., Herod died few days after the first of Nisan. In other words, the year $3 \mathrm{BC}$ was not the year of Herod's death but the beginning of the coregency and agrees with other historical facts, as discussed above. 
Also, archeological sources support the hypothesis of coregency because no coins $[22,30,52-56]$ of the reigns of Herod's sons indicate a year of reign less than five years. In other words, after Herod's death, his sons started to mint coins for the first time, although they indicated that their reign was five years old. Since $3 \mathrm{BC}$, the fourth year of coregency would be $1 \sim 2 \mathrm{AD}$, and must not be a case that the eclipse of 8-9 November, $2 \mathrm{AD}$, was visible from Palestine. As already discussed, the rabbinic tradition on Herod's death occurred on 2 Shevat-24 January $3 \mathrm{AD}$ for the Julian calendar-therefore, two and half months later than the eclipse of November $2 \mathrm{AD}$, with enough time for allowing all the facts narrated by Josephus. The fifth year of coregency would have finished at the end of Adar 3 AD, two and half months before Herod died, and therefore his sons started minting coins with indicating the fifth year of reign.

It must be noted that dating Herod's death in 4 BC contradicts all Christian chronicle tradition starting with Eusebius and Jerome. Jerome (Hieronymus, Chron., p. 252 Helm) [57] associates Herod's death with the 46th year of the reign of Augustus and with the third year of the 195th Olympic Games, therefore with 3 AD.

Furthermore, the chronology reconstructed under the hypothesis of co-regency correlates with Matthew (Mt 2,16), who mentions Herod's order to kill all children under the age of two in the Bethlehem area. This implies that Jesus was born at least two years before, practically the interval elapsed between December BC (Dionysius Exiguus' calculation) and January $3 \mathrm{AD}$, in agreement with Matthew.

Other historical facts connected to Roman and Jewish history, agreeing with Herod's death year being $3 \mathrm{AD}$ but cause chronological inconsistencies by setting his death in $4 \mathrm{BC}$, are reported by La Greca and De Caro [30]. Here, let us recall only the constraint due to the presence of Gaius Caesar in Rome in $3 \mathrm{AD}$.

Because of his several offices and missions conducted on behalf of Augustus in the East, Gaius Caesar was an important adviser of the emperor-as Josephus writes (AJ XVII. 228-229). Therefore, very likely, he should have attended the first council on deciding Herod's succession in the spring of $3 \mathrm{AD}$, when he was 22 years old, not 16 as in $4 \mathrm{BC}$.

As a last example, we consider the problem of Herod's age at his first experience as governor. According to Josephus (AJ XIV. 158), Herod the Great was appointed, by his father, governor of Galilee when he was 15, in the year when Caesar arrived in Syria, namely $47 \mathrm{BC}$, and died at the age of 70 (Josephus, $A J$ XVII. 148). If Herod died in $3 \mathrm{AD}$, at the age of 70 , then in $47 \mathrm{BC}$ he would have been $70-(47+3-1)=21$ years old, an age more plausible for the office of governor. On the contrary, the same calculation, starting from $4 \mathrm{BC}$, would yield $70-(47-4)=27$ years, and Herod would have been too old, not a very young man, as Josephus writes.

\section{Conclusions}

We have re-examined and discussed all chronological, historical and astronomical elements which, directly or indirectly, can be referred to Herod's death and determines its year. This dating affects the year of Jesus's birth and the beginning of the Christian era.

From Josephus, we know Herod the Great died after a lunar eclipse and before Passover. Since the XIX century, most scholars still assume that the eclipse mentioned by Josephus occurred on 13 March 4 BC and, consequently, Dionysius Exiguus was wrong in calculating the beginning of the Christian era-by four years at least-because Herod must have been alive when Jesus was born.

For solving the apparent incompatibility of the historical facts narrated by Josephus with the date of the eclipse today mostly accepted (13 March 4 BC) and a too-near Passover (12 April 4 BC), facts unlikely possible in less than a month, we have determined an alternative date by examining the eclipses visible from Jerusalem in near years. This analysis-supported by simulation of naked-eye visibility of lunar eclipses, extensively reported in Appendix A-has shown that the most eligible eclipse associable to Herod's death occurred on the night $8-9$ November 2 AD. 
Our novel modelling of naked-eye visibility of partial eclipses (reported in Appendix A) has ruled out the eclipse of $4 \mathrm{BC}$ because, very likely, it was not recognized as an eclipse by occasional observers, but confused with a full Moon.

Besides this objective astronomical finding, our conclusion is also supported by the correlation between segmented sleep and eclipse intervals; by its compatibility with the long sequence of events narrated by Josephus and with the rabbinic tradition about Herod's death. This date also agrees with other historical facts connected to Roman and Jewish history.

In conclusion, Herod the Great must have died at the beginning of $3 \mathrm{AD}$ and, very likely, Dionysius Exiguus was correct in calculating the beginning of the Christian era.

Author Contributions: All authors have contributed to discuss the results and write the paper. L.D.C. performed the theoretical calculations. All authors have read and agreed to the published version of the manuscript.

Funding: This research received no external funding.

Informed Consent Statement: Not applicable.

Conflicts of Interest: The authors declare no conflict of interest.

\section{Appendix A. Modeling Naked-Eye Vision of Partial Lunar Eclipses}

The naked-eye human visual system differs from the digital camera visual system in spatial resolution, brightness, sensitivity, dynamic range, color perception and nonlinearity [58]. By considering all these differences, in this Appendix, we study how a partial lunar eclipse is seen by naked eyes. Three main issues must be discussed:

(1) Characteristics of full-Moon image suitable for simulating, from digital photographs, how it is seen by naked eyes;

(2) Effects of human visual system such as: angular acuity, dynamic range, luminosity adaption, non-linear brightness perception;

(3) Luminosity variation of the Moon during a partial eclipse.

We will see that the naked-eye-perceived gray tones of the Moon in the Earth's umbra, during a partial eclipse, are not linearly related to the actual luminance levels. For low umbral magnitudes, this effect could makes the eclipse very difficult to be recognized by an occasional observer of the night sky.

\section{Appendix A.1. Characteristics of Full-Moon Image}

A large number of digital photographs of the entire Moon have been recently studied, to verify if they represent quantitatively some physical properties, e.g., its luminance [58]. Therefore, for simulating as it is seen with naked eyes, we started from a digital photography of the Moon, characterized by $1024 \times 1024$ pixels, each pixel coded with eight bits to represent gray $2^{8}=256$ luminance levels, but suitably modifying digital image resolution, gray levels and dynamical range to reproduce the characteristics of naked-eye vision.

The full Moon, seen from the Earth, subtends an angle of about $0.5^{\circ}$ (i.e., it is seen under an angle of 30 arcminutes). By the naked eyes it is seen with an angular resolution of $42 \operatorname{arcsec}$ (60 arcseconds make 1 arcminute, 3600 arcseconds make a degree), corresponding to a visual acuity of $3600 / 42 \cong 86$ cycles per degree [35]. At the Nyquist angular frequency, samples must be taken every 21 arcsec, therefore the diameter of the Moon requires only $1800 / 21 \cong 86$ pixels to simulate how it would be seen by naked eyes, much fewer than the digital resolution allowed by a digital camera. Thus, a $1024 \times 1024$ digital photograph of the Moon-used in our processing - has more spatial details than the human visual system can appreciate; therefore, the photograph must be subsampled (i.e., adjacent pixels must be averaged) to simulate naked-eye human vision, from $1024 \times 1024$ to $86 \times 86$ pixels.

The average luminance of the full Moon is $3670 \mathrm{~cd} / \mathrm{m}^{2}$. This value corresponds to a visual magnitude $m=-12.73$ [59]. Visual acuity (i.e., the human ability to distinguish spatial details) is a function of the luminance. The brightness of the Moon during a partial eclipse can vary up to about 10 magnitudes (see next sub-section for more details), reaching 
the minimum value of $m=-2 \sim-3$ in total eclipses. This is equivalent to change in the Moon's luminance by a factor of $2.512^{10} \sim 10,000$ [59]. Figure A1 shows the reduction $(\%)$ of the relative visual acuity (VA) versus the average luminance, from its maximum value-corresponding to the average full- Moon luminance, $m=-12.73$ - to its minimum value-corresponding to total lunar eclipse, $m=2 \sim 3$. The calculation is based on the mathematical relationship between luminance $L$ and maximum resolvable frequency [58], and leads to the following formula (log = natural logarithm), plotted in Figure A1:

$$
\frac{V A\left(L_{\text {full-moon }}\right)-V A(L)}{V A\left(L_{\text {full-moon }}\right)}=0.451-0.325 \times \arctan (0.350+0.608 \times \log (L))
$$

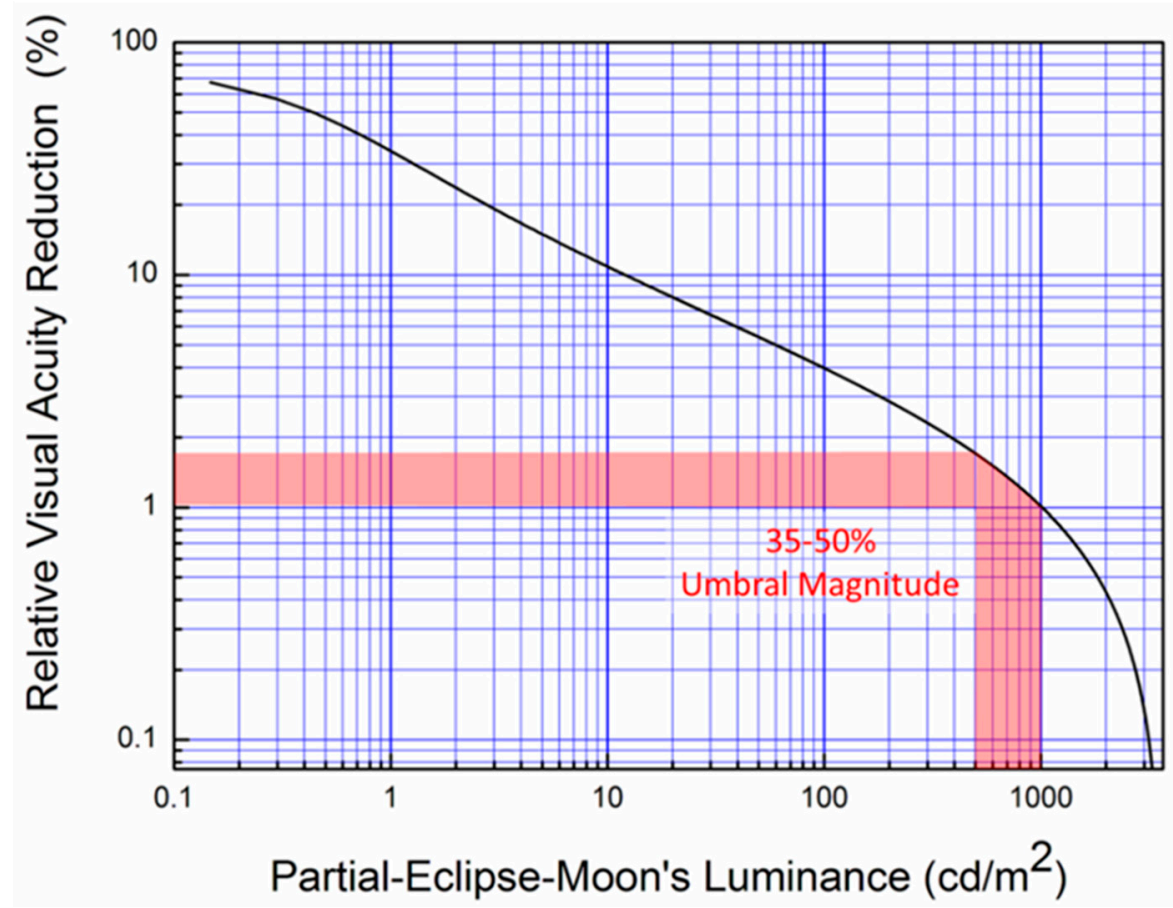

Figure A1. Relative visual acuity reduction (\%), with respect to the full-Moon value, as a function of the average Moon luminance during partial lunar eclipses.

In Figure A1, we notice that when a total eclipse is approached (leftmost part of the curve) the visual acuity is reduced by almost $70 \%$ compared to full-Moon value, corresponding to an angular resolution slightly worse than 60 arcseconds, a value usually associated by astronomers to scotopic vision of stars visible with naked eyes. However, for partial lunar eclipses with an umbral magnitude in the range $35 \sim 50 \%$, the Moon luminance [59] is about $500 \sim 1000 \mathrm{~cd} / \mathrm{m}^{2}$, implying a negligible reduction, of the order of $1 \sim 2 \%$ of the $V A$ value at the full-Moon visual magnitude, as it can be seen in Figure A1. Therefore, in our simulations of partial lunar eclipses, visual acuity can be assumed roughly constant when the umbral magnitude is less than $50 \%$, as we do in the following.

A second aspect to consider is that a typical observer can distinguish only about 24 intensity values [60], equivalent to gray levels quantized with 5 bits. However, with 5 bits, false contours may appear in the image, so that we need at least 6 bits to avoid them. Therefore, with a histogram transform, we convert 8-bit photographs to 6-bit images, detailed enough to simulate naked-eye vision.

A third aspect to consider is how different regions of the Moon surface reflect light. During a full-Moon, the darker regions have magnitudes $0.3 \sim 0.4$ less than the more luminous regions [35,61]. Now, because in the magnitude scale the next value is 2.512 larger than the preceding one, the average value of gray levels to be associated with the darkest 
regions of digital photographs is that of the most luminous regions reduced by about $70 \sim 75 \%$, because $2.512^{-0.3}=0.76$, i.e., $76 \%$, and $2.512^{-0.4}=0.69$, i.e., $69 \%$.

In conclusion, after all the processing just discussed, we obtain a digital model of the entire Moon surface which, in a point of pixel coordinates $(x, y)$, the corresponding gray level $I(x, y)$ is proportional to the luminance of the Moon $L(x, y)$ [58], suitable for simulating naked-eye vision. However, it is not necessary to know the constant of proportionality because, as we show in the next subsection, only relative values count.

\section{Appendix A.2. Brightness Adaption and Discrimination}

Experimental evidence shows that the subjective brightness $B$ (the intensity perceived by human visual system), concerning a source with luminance $L$, is a non-linear function of light intensity. The relation between $B$ and $L$ is usually modeled with either a logarithmic or a power law [60,62-64]. In passing from scotopic (rod-mediated) to photopic vision (cone-mediated), the human visual system adapts to a very large luminance range, from $10^{-6}$ to $10^{4} \mathrm{~mL}$. The transition between the two types of vision occurs in the mesopic range $10^{-3}$ to $10^{-1} \mathrm{~mL}$, where the vision is mediated by both cones and rods.

Here, we are mainly interested in the mesopic vision because its luminance levels are typical both of full Moon and partial lunar eclipses with umbral magnitude of $0 \sim 0.5$. It is important to recall that our visual system cannot work simultaneously in the entire luminance range $10^{-6}$ to $10^{4} \mathrm{~mL}$, but, for optimal results, adapts itself to smaller intervals around an average value $L_{a}$ which characterizes the scene under observation (e.g., during night), a phenomenon known as brightness adaption. Now, the human visual system can perceive, simultaneously, only a 100 to 1 luminance range [65]. For this reason, in astronomy, the magnitude of stars visible with naked eyes, since ancient times, is classified in $n=6$ classes, where the next class is 2.512 brighter than the previous one, so that $2.512^{n-1}=100$.

Here, we are interested in a relative brightness range $\left[B_{\min }, B_{\max }\right]$ for any luminance adaptation level $L_{a}$, with a light signal appearing black below the threshold level $B_{\text {min }}$, and white above $B_{\max }$. This relative brightness is different from the nominal brightness, e.g., the visual magnitude $m=-12.73$ associated in astronomy to full Moon.

According to Weber and Fechner's law, brightness is related to luminance by a logarithmic relation $B=k \log L$, with $k$ a constant [66]. Now, the log-values of light intensity, air-mass-corrected, coming from point-like light sources - such as brighter planets or first magnitude stars - versus visual magnitudes can be very well modeled by a straight line with unit slope [59], therefore implying $k \cong 1$. Thus, with $k=1$ and $a=2.512$ being the base of logarithms, we can write the following relationship:

$$
\frac{a^{B}-a^{B_{\min }}}{a^{B_{\max }}-a^{B_{\min }}}=\frac{L-L_{\min }}{L_{\max }-L_{\min }}
$$

Because $L_{\min } \ll L_{\max }$, we can set $L_{\max }-L_{\min } \cong L_{\max }$, i.e., $L_{\min } \cong 0$. Now, by defining the relative (normalized) luminance $L_{n}=L / L_{\max }, L_{n}$ varies in the normalized range 0 to 1 . Therefore, from Equation (A2), we get:

$$
\frac{a^{B}-1}{a^{B_{\max }}-1}=\frac{L}{L_{\max }}
$$

Thus:

$$
B_{\log }=\log _{a}\left[1+c \times L_{n}\right]
$$

The scaling factor $c$ is given by:

$$
c=\left(a^{B_{\max }}-1\right)
$$


Here, the subscript "log" means that the modeling assumes the logarithmic relationship between brightness and luminance.

For $L_{n}=0$, Equation (A4) gives the dark threshold level, a perceived zero brightness $B_{\text {log }}=0$. For $L_{n}=1$ Equation (A4) gives $B_{\log }=B_{\max }$, corresponding either to glaringly white or to maximum luminance seen in a complex scene. Moreover, for a complex scene such as a full Moon in night (dark) sky, we can assume $L_{n}(x, y)=I(x, y)$, where $I(x, y)$ is the intensity of the image of the full Moon in a digital photograph, but suitably rescaled and resampled, as discussed in the previous sub-section. Therefore, Equation (A4), applied to a "linear" gray-level image of the Moon, during a partial eclipse, can simulate non-linear effects of naked-eye vision in a small relative brightness range, under the assumption of a logarithmic human visual response.

However, the relationship between brightness and luminance can be also modeled with a power law $B \equiv L^{r}$, with $r=0.33$ for a $5^{\circ}$ uniformly-illuminated patch located in a larger dark background [63], and $r=0.5$ (corresponding to taking the square root of the luminance) for a point-like object [63]. Moreover, for complex scenes seen in the mesopic range, the exponent is 0.67 [67]. The full Moon is seen under $0.5^{\circ}<<5^{\circ}$, but cannot be assimilated to a point-like object $\left(0.5^{\circ}=1800\right.$ arcseconds $)$ because the angular resolution (acuity) of human vision is 42 arcseconds at the luminance value associated with a full Moon [35]. Therefore, $r=0.5$-the average value between 0.33, 0.5 and 0.67 , previously cited-seems to be the best compromise when seeing complex scenes in the mesopic vision range, applicable when observing a partial lunar eclipse.

Thus, as for Equations (A1)-(A3), by assuming a power-law relationship between brightness and luminance, in the relative brightness range $\left[B_{\min }, B_{\max }\right]$, we obtain:

$$
B_{\text {power }}(L)=\left(1+c^{\prime} \times L_{n}\right)^{r}-1
$$

The scaling factor $c^{\prime}$ is given by:

$$
c^{\prime}=\left(1+B_{\max }\right)^{1 / r}-1
$$

As already stated, we are concerned with simulating partial lunar eclipses with umbral magnitude smaller than 0.5. In this case, experimental and theoretical works show that the variation in visual magnitude $\Delta m$ when the Moon passes from the penumbral region to the umbra region, is about $1 \sim 1.5$ [59]. Therefore, setting the value of $B_{\max } \approx \Delta m$ from Equation (A5), we obtain an estimate of the scale factor $c=1.5 \sim 3$, and from Equation (A7) we obtain $c^{\prime}=3 \sim 5$.

Figure A2 shows the logarithm, the square root $(r=0.5)$ and the linear responses for comparison.

Figure A3 shows the relative visual responses of logarithm and square root cases versus normalized luminance. We can notice that these responses are expected to be larger for smaller normalized luminance values. In other words, in complex scenes, the perception of lower luminosity levels is the most affected, enhanced with respect to medium and high luminance levels. The latter levels are the least affected because of the adaption to the average luminance level of the observed scene. This is true until the luminance level does not exceed the maximum value allowed by the cone-mediated vision, when saturation occurs, such as looking directly at the Sun. However, in the mesopic vision of partial lunar eclipses, we are very far from this limiting situation.

Now, to complete our modeling of naked-eye vision of lunar partial eclipses, simulated from digital photographs, we need only to model the variation of Moon luminance in the Earth's umbra. 


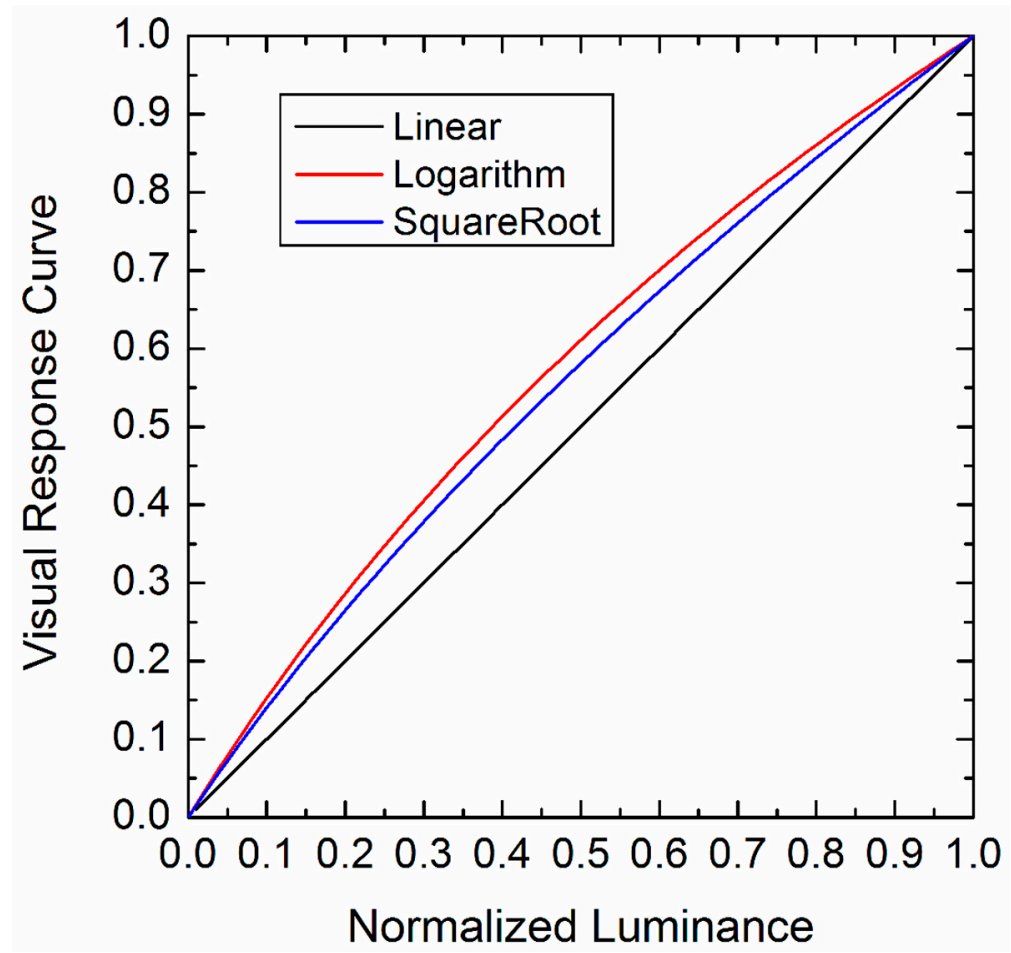

Figure A2. Linear (black curve), logarithm (red curve) and power law (blue curve) with $r=0.5$ (square root) responses of human vision versus normalized luminance, when observing a complex scene.

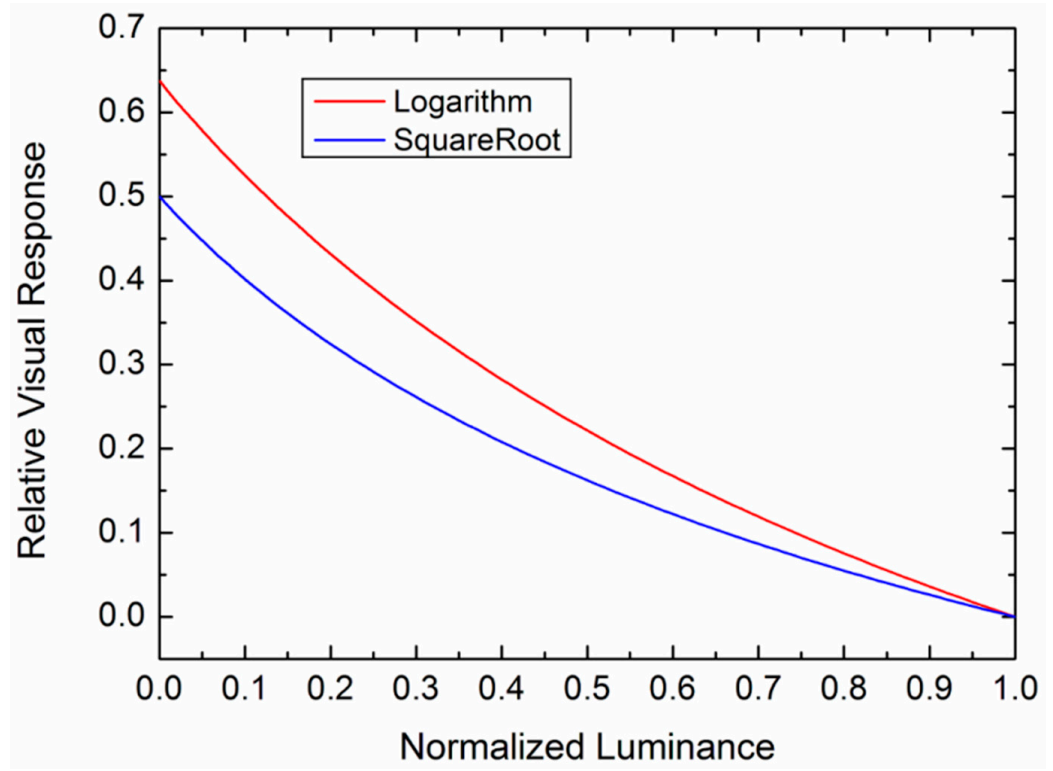

Figure A3. Relative visual responses of logarithm and square root cases versus normalized luminance.

Appendix A.3. Partial Lunar Eclipses Seen by Naked Eyes

The simulation of partial lunar eclipse is based on measurements and models of light radiance during eclipses [68], obtained by converting solar irradiance on the Moon surface to the irradiance on the Earth surface due to the Moon, converted in visual magnitude [59]. The light that illuminates the eclipsed Moon varies largely because of many factors: Sun-Earth-Moon distances, surface pressure and vertical temperature structure of the atmosphere, the concentration and height of ozone and aerosol particles [68]. However, these effects modify by only few percentage points the visual magnitude variations in partial eclipses with umbral magnitudes smaller than $50 \%$. Moreover, occasional observers 
perceive variations in the brightness of the Moon disk only relative to the full Moon seen one or two hours before or after the eclipse. Therefore, seasonal variations in the Moon's brightness due either to different Sun-Moon-Earth distances or to different atmospheric conditions do not affect our analysis and can be neglected.

Figure A4 shows typical brightness values in visual magnitudes of lunar eclipses. Points are experimental data taken from Hernitschek, Schmidt and Vollmer'work (2008).

\section{Earth's Penumbra}
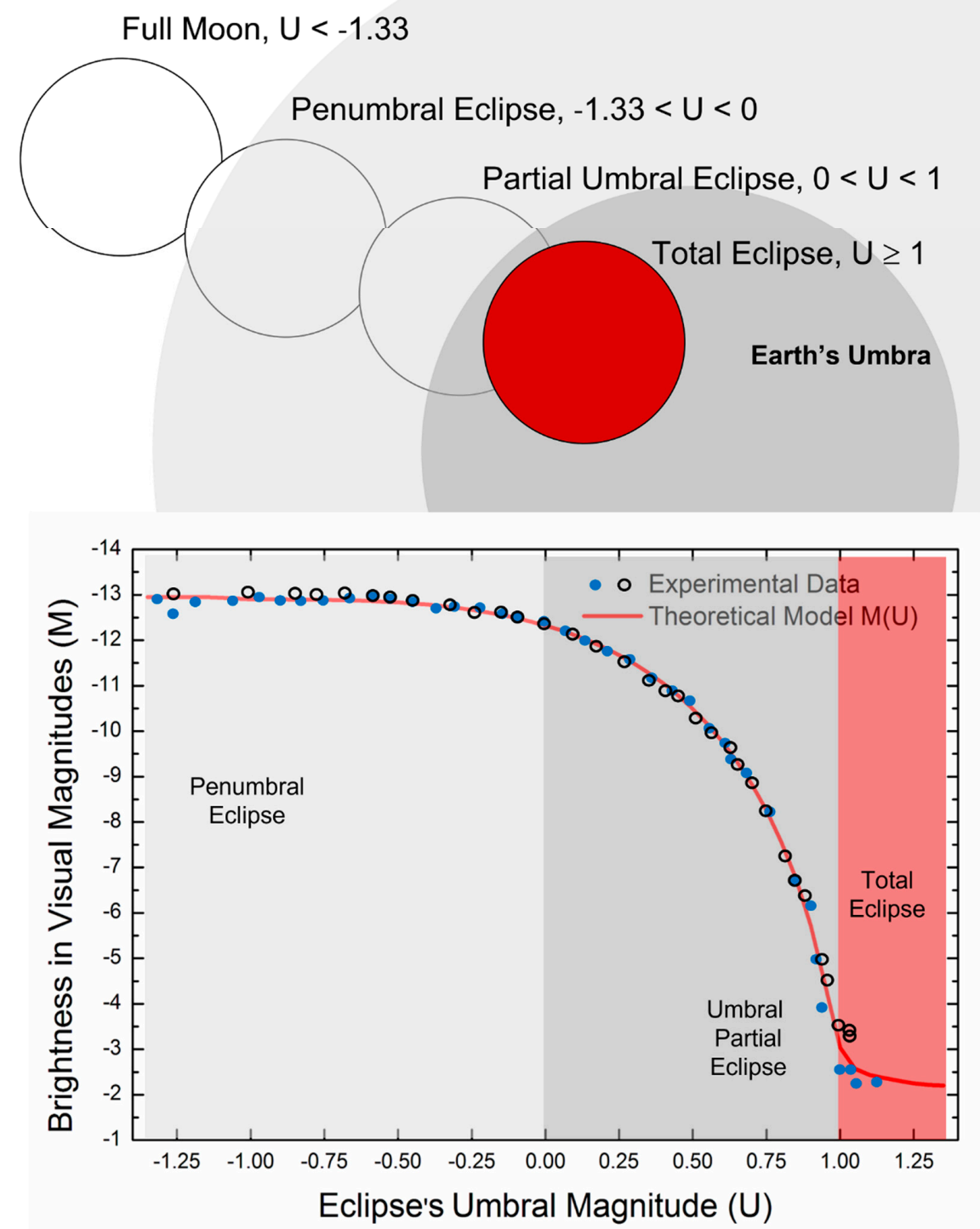

Figure A4. Brightness in visual magnitudes of lunar eclipses: circles refer to experimental data taken from Hernitschek, Schmidt and Vollmer'work (2008); the continuous curve refers to an eclipse light model, derived from the solar irradiance model on Moon surface by Vollmer and Gedzelman (2008), setting visual magnitude proportional to solar irradiance.

The continuous curve is a model of the eclipse light obtained by setting the visual magnitudes of the eclipsed Moon proportional to the normalized solar irradiance on its surface [68], by imposing that the maximum visual magnitude, i.e., the full-Moon value, corresponds to the maximum normalized solar irradiance. We note that, for partial lunar eclipses, the predictions of the model are very accurate. This result implies that, for partial eclipses, the solar irradiance is the main factor in determining the Moon's visual magnitude [68]. 
Moreover, from Figure A4, it follows that, during the penumbral phase, the Moon's visual magnitude changes so slowly and so little that penumbral eclipses are not recognizable by a naked-eye occasional observer. On the contrary, during the umbral phase, the Moon's visual magnitude varies consistently, about two classes, when the umbral magnitude ranges from 0 to 0.5 .

To simulate an image of a partial lunar eclipse, we multiply the model of the full Moon by a 2D luminance damping function, therefore describing the Earth umbra and penumbra effects on Moon luminance. This function is obtained by an azimuthal rotation of the eclipse light curve model, represented in Figure A4, around the center of the Earth umbra. The result is shown in Figure A5, together with the Moon, to provide a reference size-scale.

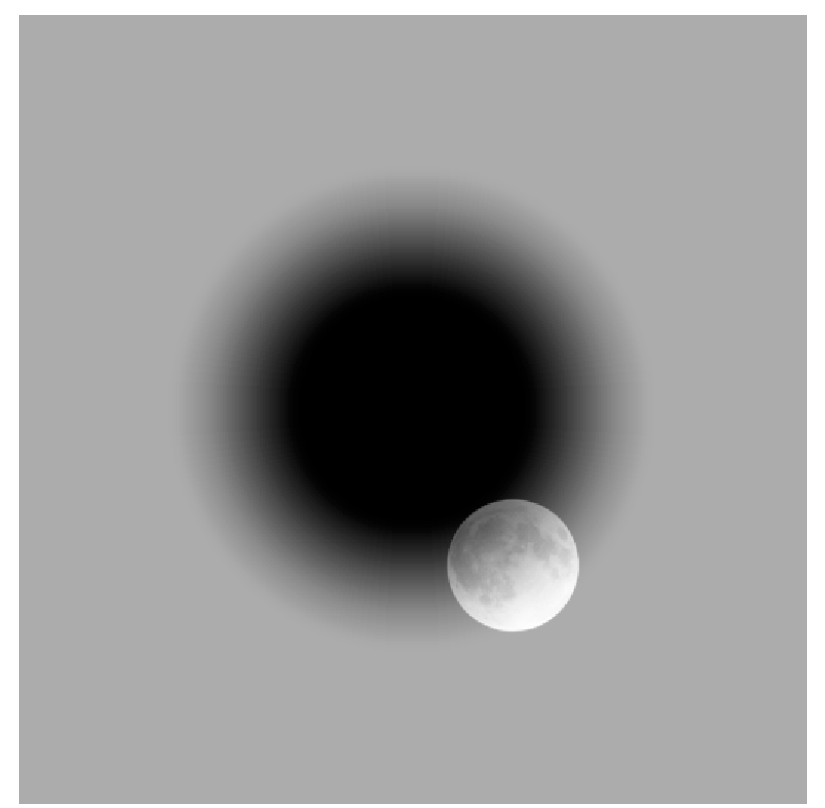

Figure A5. Visual representation of the Earth umbra-penumbra model, used to calculate partial eclipse luminance. The superposed image of the full Moon sets the scale in the Earth umbrapenumbra model.

The so-obtained normalized linear 2D Earth umbra-penumbra model can be multiplied by the normalized image of the full Moon, to simulate an image of the eclipse with a "linear" visual response. Indeed, to simulate the non-linear response of human vision to different luminance levels, we can apply either Equation (A4) (logarithm model), or Equation (A6) (power-law model) to the gray levels of the image of the eclipse obtained with a "linear" visual response.

Figure A6 reports the sequence of lunar disks seen with naked eyes for the eclipses of $4 \mathrm{BC}$ (left) and $2 \mathrm{AD}$ (right), discussed in the main text. In the upper panel, the two sequences are due to the linear response of the human visual system; in the middle panel they are due to the logarithmic response; in the lower panel they are due to the power-law visual (square root, $r=0.5$ ) response. Both for the logarithmic and power-law models, the partial eclipse of 4 BC, largely associated with Herod's death, could not be easily perceived as an eclipse because the Moon's aspect looks quite similar to a full Moon. On the other hand, both the logarithmic and power-low models show that the partial eclipse of $2 \mathrm{AD}$, associated to Herod's death by Fedalto, could be perceived as an eclipse, even if it seen with naked eyes, because the Moon's aspect is very different from that of a full Moon, due to the neat presence of an unusual concave dark region, which would have likely alerted an occasional observer. 


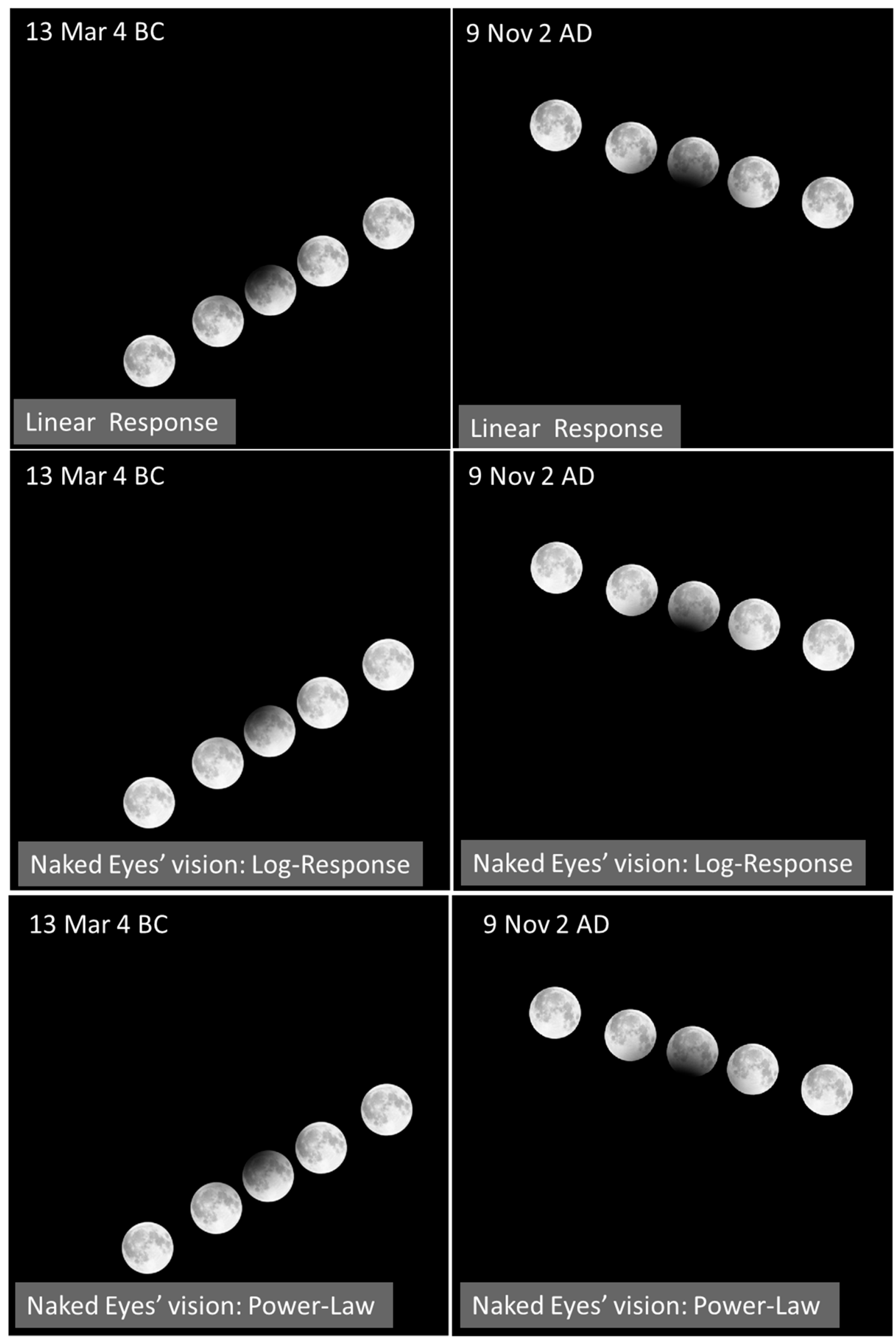

Figure A6. Upper panel: output of the linear response for the eclipse of 4 BC (left) and 2 AD (right), discussed in the main text. Middle panel: simulations obtained for the two eclipses applying Equation (A4), i.e., under the hypothesis of a logarithmic response of the human visual system. Lower panel: simulation for the two eclipses under the hypothesis of a power-law visual response, obtained applying Equation (A6). 


\section{References}

1. Krusch, B. Die Einführung des griechischen Paschalritus im Abendiande. Neues Arch. 1884, 9, 99-169.

2. Schwartz, E. Christliche und Jüdische Ostertafeln; Weidmann: Berlin, Germany, 1905; p. 22.

3. Ginzel, F.K. Handbuch der Mathematischen und Technischen Chronologie; Hinrichs: Leipzig, Germany, 1906; Volume 3, pp. 177-248.

4. Jones, C.W. The Victorian and Dionysiac Paschal Tables in the West. Speculum 1934, 9, 408-421. [CrossRef]

5. Krusch, B. Studien zur Christlich-Mittelalterlichen Chronologie. Die Entstehung Unserer Heutigen Zeitrechnung; Verlag der Akademie der Wissenschaften: Berlin, Germany, 1938; pp. 53-86.

6. Grumel, V. La Chronologie; Presses Universitaires de France: Paris, France, 1958; p. 224.

7. Pedersen, O. The Ecclesiastical Calendar and the Life of the Church. In Gregorian Reform of the Calendar; Coyne, G.V., Hoskin, M.A., Pedersen, O., Eds.; Pontificia Academia Scientiarium: Vatican City, Vatican, 1983; pp. 17-74.

8. Richards, E.G. Mapping Time. The Calendar and Its History; Oxford University Press: Oxford, UK, 2000.

9. Declercq, G. Anno Domini. The Origins of the Christian Era; Brepols: Turnhout, Belgium, 2000.

10. Declercq, G. Dionysius Exiguus and the Introduction of the Christian Era. Sacris Erudiri 2002, 41, 165-246. [CrossRef]

11. Giorgio, F. Da Pasqua il Tempo Nuovo. Questioni di Cronologia Ebraico-Cristiana; Mazziana: Verona, Italy, 2012 ; pp. 51-71.

12. Cappelli, A. Cronologia, Cronografia e Calendario Perpetuo. Dal Principio dell'era Cristiana ai Nostri Giorni, 7th ed.; Hoepli: Milano, Italy, 2012.

13. Schürer, E. A History of the Jewish People in the Time of Jesus Christ; Charles Scribner's Sons: New York, NY, USA, 1891; Volume I, p. 465.

14. Barnes, T.D. The Date of Herod's Death. J. Theol. Stud. 1968, 19, 204-209. [CrossRef]

15. Firpo, G. La data della morte di Erode il Grande. Osservazioni su alcune recenti ipotesi. Studi Senesi 1983, 95, 87-104.

16. Finegan, J. Handbook of Biblical Chronology. Principles of Time Reckoning in the Ancient World and Problems of Chronology in the Bible; Revised Edition; Hendrickson Publishers: Peabody, MA, USA, 1998.

17. Nollet, J.A. The Astronomical and Historical Evidence for Dating the Nativity in 2 BC. Perspect. Sci. Christ. Faith 2012, 62, 211-219.

18. Sticka, S. Segmented Sleep in First-Century Roman Society. Master's Thesis, Graduate School of Arts and Sciences, Brandeis University, Waltham, MA, USA, 2017. Available online: http:/ / bir.brandeis.edu/handle/10192/33877 (accessed on 20 April 2021).

19. Worthman, C.M. The Evolutionary Ecology of Human Sleep. In Evolutionary Medicine and Health; Trevathan, W.R., Smith, E.O., McKenna, J.J., Eds.; Oxford University Press: Oxford, UK, 2008; pp. 291-313.

20. Holladay, W.L. Indications of Segmented Sleep in the Bible. Cathol. Biblical Q. 2007, 69, 215-221.

21. Caspari, C.E. Chronologisch-Geographische Einleitung in Das Leben Jesu Christi; Agentur des Rauhen Hauses: Hamburg, Germany, $1869 ;$ p. 21.

22. Pratt, J.P. Yet another Eclipse for Herod. Planetarian 1990, 19, 8-14.

23. Kushnir-Stein, A. Josephus' Evidence for the date of Herod's Death. Scr. Class. Isr. 1995, 14, 73-86.

24. Steinmann, A.E. When Did Herod the Great Reign? Novum Testam. 2009, 51, 1-29. [CrossRef]

25. Martin, E.L. The Birth of Christ Recalculated; Foundation for Biblical Research: Pasadena, CA, USA, 1980; pp. 29-34.

26. Martin, E.L. The Nativity and Herod's Death. In Chronos, Kairos, Christos: Nativity and Chronological Studies Presented to Jack Finegan; Vardaman, J., Yamauchi, E.M., Eds.; Eisenbrauns: Winona Lake, IN, USA, 1989; pp. 85-92.

27. Filmer, W.E. The Chronology of the Reign of Herod the Great. J. Theol. Stud. 1966, 17, 283-298. [CrossRef]

28. Bernegger, P.M. Affirmation of Herod's Death in 4 B.C. J. Theol. Stud. 1983, 34, 526-531. [CrossRef]

29. Fedalto, G. Storia e Metastoria del Cristianesimo. Questioni Dibattute; Mazziana: Verona, Italy, 2006; pp. 54-57.

30. La Greca, F.; De Caro, L. La datazione della morte di Erode e l'inizio dell'era cristiana. Ann. Theol. 2019, 33, 11-54.

31. Schaefer, B.E. Lunar Visibility and the Crucifixion. Q. J. R. Astron. Soc. 1990, 31, 53-67.

32. Schaefer, B.E. Glare and Celestial visibility. Publ. Astron. Soc. Pac. 1991, 103, 645-660. [CrossRef]

33. Meeus, J. Astronomical Algorithms, 2nd ed.; Willmann-Bell Inc.: Richmond, VA, USA, 1998.

34. Fedalto, G. Quando è morto Gesù. Studia Patav. 2001, 48, 621-629.

35. Schaefer, B.E. The Length of the Lunar Month. Archaeoastron. Suppl. J. Hist. Astron. 1992, 23, S32-S42. [CrossRef]

36. Wehr, T.A. In Short Photoperiods, Human Sleep is Biphasic. J. Sleep Res. 1992, 1, 103-107. [CrossRef]

37. Paul, B. Concepts of Time among the Tiv of Nigeria. Southwest. J. Anthropol. 1953, 9, 251-262.

38. Ekirch, A.R. Sleep We Have Lost: Pre-Industrial Slumber in the British Isles. Am. Hist. Rev. 2001, 106, 343-386. [CrossRef]

39. Ekirch, A.R. At Day's Close: Night in Times Past, 1st ed.; W. W. Norton \& Company: London, UK, 2005.

40. Nissin, L. Sleeping Culture in Roman Literary Sources. Arctos 2015, 49, 95-133.

41. Wright, K.P., Jr.; McHill, A.W.; Birks, B.R.; Griffin, B.R.; Rusterholz, T.; Chinoy, E.D. Entrainment of the Human Circadian Clock to the Natural Light-Dark Cycle. Curr. Biol. 2013, 23, 1554-1558. [CrossRef]

42. De la Iglesia, H.O.; Fernández-Duque, E.; Golombek, D.A.; Lanza, N.; Duffy, J.F.; Czeisler, C.A.; Valeggia, C.R. Access to Electric Light is Associated with Shorter Sleep Duration in a Traditionally Hunter-Gatherer Community. J. Biol. Rhythm. 2015, 30, 342-350. [CrossRef] [PubMed]

43. Yetish, G.; Kaplan, H.; Gurven, M.; Wilson, C.; McGregor, R.; Siegel, J.M. Natural Sleep and Its Seasonal Variations in Three Pre-industrial Societies. Curr. Biol. 2015, 25, 2862-2868. [CrossRef]

44. Schwartz, D.R. Studies in the Jewish Background of Christianity; J.C.B. Mohr: Tübingen, Germany, 1992.

45. Vanderkam, J.C. From Joshua to Caiaphas: High Priests after the Exile; Fortress Press: Minneapolis, MN, USA, $2004 ;$ p. 410. 
46. Parker, R.A.; Dubberstein, W.H. Babylonian Chronology 620 B.C.-A.D. 75; Brown University Press: Providence, RI, USA, 1956.

47. La Greca, F.; De Caro, L. Nuovi studi sulla datazione della crocifissione nell'anno 34 e della nascita di Gesù il 25 dicembre dell'1 AC. Ann. Theol. 2017, 31, 11-52.

48. Zeitlin, S. Megillat Taanit as a Source for Jewish Chronology and History in the Hellenistic and Roman Periods. Master's Thesis, Dropsie College, Philadelphia, PA, USA, 1922; p. 108.

49. Noam, V. Megillat Taanit-The Scroll of Fasting. In The Literature of the Jewish People in the Period of the Second Temple and the Talmud. The Literature of the Sages; Second Part; Safrai, S., Ed.; Van Gorcum Fortress Press: Assen, The Netherlands, 2006; Volume 3, pp. 339-362.

50. Doggett, L.E.; Schaefer, B.E. Lunar Crescent Visibility. Icarus 1994, 107, 388-403. [CrossRef]

51. Wright, A.G.; Murphy, R.E.; Fitzmyer, J.A. Una Storia di Israele. In Nuovo Grande Commentario Biblico; Brown, R.E., Fitzmyer, J.A., Murphy, R.E., Eds.; Queriniana: Brescia, Italy, 2002; pp. 1637-1642.

52. Kindler, A. A Coin of Herod Philip-The Earliest Portrait of a Herodian Ruler. Isr. Explor. J. 1971, 21, 161-163.

53. Meshorer, Y. Ancient Jewish Coinage. Volume II: Herod the Great through Bar Cochba; Amphora Books: New York, NY, USA, 1982; p. 36.

54. Alteri, G. La Circolazione Monetaria. In Le Monete del Tempo di Gesù; Alteri, G., Ed.; Eupremio Montenegro Editore: Torino, Italy, 1998; pp. 23-25.

55. Hendin, D. Guide to Biblical Coins, 5th ed.; Amphora Books: New York, NY, USA, 2010; p. 250.

56. Ariel, D.T.; Fontanille, J.-P. The Coins of Herod. A Modern Analysis and Die Classification; Brill: Leiden, The Netherlands, $2012 ;$ p. 186.

57. Helm, R. Eusebius Werke 7: Die Chronik des Hieronymus; Akademie Verlag: Berlin, Germany, 1956; p. 252.

58. Ackermann, J.; Goesele, M. How Bright Is the Moon? Recovering and Using Absolute Luminance Values from Internet Images. In Computational Color Imaging, Proceedings of the 4th International Workshop, CCIW, Chiba, Japan, 3-5 March 2013; Tominaga, S., Schettimi, R., Trémeau, A., Eds.; Springer: Berlin, Germany; 2013; pp. 90-104.

59. Hernitschek, N.; Schmidt, E.; Vollmer, M. Lunar Eclipse Photometry: Absolute Luminance Measurements and Modeling. Appl. Opt. 2008, 47, H62-H71. [CrossRef] [PubMed]

60. Gonzalez, R.C.; Woods, R.E. Digital Image Processing; Addison-Wesley: Reading, MA, USA, 1992; pp. 38-40, 90-95.

61. Montañés-Rodríguez, P.; Pallé, E.; Goode, P.R. Measurements of the Surface Brightness of the Earthshine with Applications to calibrate Lunar Flashes. Astron. J. 2007, 134, 1145-1149. [CrossRef]

62. Stevens, J.C.; Stevens, S.S. Brightness function: Effects of Adaptation. J. Opt. Soc. Am. 1963, 53, 375-385. [CrossRef]

63. Stevens, S.S. Duration, Luminance and the Brightness Exponent. Percept. Psychophys. 1966, 1, 96-100. [CrossRef]

64. Bartleson, J.C.; Breneman, E.J. Brightness Perception in Complex Fields. J. Opt. Soc. Am. 1967, 57, 953-957. [CrossRef] [PubMed]

65. Bartleson, J.C.; Grum, F. (Eds.) Optical Radiation Measurements. Vol. 5. Visual Measurements; Academic Press, Inc.: Orlando, FL, USA, 1984.

66. Portugal, R.D.; Svaiter, B.F. Weber-Fechner Law and the Optimality of the Logarithmic Scale. Minds Mach. 2011, $21,73-81$. [CrossRef]

67. Hecht, S. The Visual Discrimination of Intensity and the Weber-Fechner Law. J. Gen. Physiol. 1924, 7, 235-267. [CrossRef]

68. Vollmer, M.; Gedzelman, S.D. Simulating Irradiance during Lunar Eclipses: The Spherically Symmetric Case. Appl. Opt. 2008, 47, H52-H61. [CrossRef] 